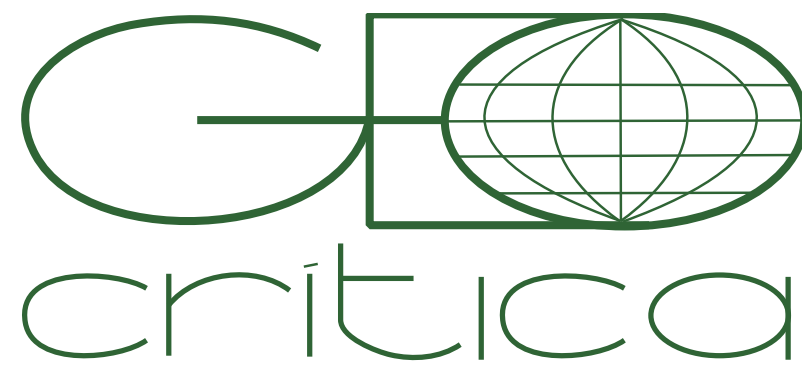

\section{Scripta Nova}

Revista Electrónica de Geografía y Ciencias Sociales Universitat de Barcelona

ISSN: $1138-9788$

Vol. 25, Núm. 4 (2021), p. 147-182

\title{
(RE)PENSANDO EL DERECHO A LA CIUDAD DESDE LOS CENTROS SOCIALES OKUPADOS
}

\author{
Aritz Tutor Anton \\ Euskal Herriko Unibertsitatea/Universidad del País Vasco \\ alsumak@gmail.com
}

Recibido: 1 febrero 2021; Devuelto para correcciones: 16 abril 2021; Aceptado: 23 noviembre 2021

Re(pensando) el derecho a la ciudad desde los centros sociales okupados (Resumen)

El derecho a la ciudad se ha convertido en un marco de significado tan amplio que ha perdido parte de su sentido y de su fuerza transformadora. Con tal de aproximarnos a una experiencia que pueda conectar con el concepto primigenio de Lefebvre y reivindicar su vigencia, tomaremos como referencia los Centros Sociales Okupados (CSO). Estos son la prueba de la importancia de espacializar el derecho a la ciudad, con infraestructuras que mantengan las tradiciones combativas y continúen las diversas luchas. En concreto, y para comprender mejor el alcance de este planteamiento teórico, el artículo estudia dos Centros Sociales Okupados en la ciudad de Barcelona, La Vaina y Can Masdeu. El texto cierra con unas conclusiones en el que se sintetizan los principales resultados: que la disputa por lo urbano pasa por apelar a las dimensiones concretas de los derechos y que los Centros Sociales Okupados, como espacios de y para el encuentro, juegan ese rol.

Palabras clave: espacialidades; Barcelona; okupación; colectividad; encuentro.

Quiero agradecer a Rolando Espinosa Hernández por su lectura atenta y sus certeros comentarios, que ayudaron a reorientary mejorar notablemente el texto.

\section{(Re)thinking the right to the city from the Squatting Social Centers (Abstract)}

The right to the city has become such a broad framework that it has lost part of its meaning and transforming power. In order to approach an experience that can connect with Lefebvre's original concept and vindicate its validity, we will take Squatting Social Centers as a reference. These Centers are a proof of the importance of spatializing the right to the city, with infrastructures that maintain combative traditions and continue a variety of struggles. Specifically, and to better understand the scope of this theoretical approach, this paper studies two Squatting Social Centers in the city of Barcelona: La Vaina and Can Masdeu. The main results are synthesized in the final conclusions: that the dispute over the urban involves appealing to the specific dimensions of rights and that the Squat Social Centers, as spaces of and for the encounter, play that role. Keywords: spatialities; Barcelona; squatting; community; encounter. 
El derecho a la ciudad, noción proveniente del mundo académico, se ha popularizado (Marcuse 2009; Goonewardena 2011; Díaz-Parra y Jover 2021) y se ha ido incorporando a ámbitos dispares como el político, el periodístico, el gubernamental (Wigle y Zárate 2010), el institucional (HIC-AL 2008) o el activista (Mundial 2005), hasta abarcar múltiples (y a veces contradictorias) aspiraciones (Simone 2005). Ello comporta el riesgo de desactivar un concepto poderoso (Mayer 2009) y convertirlo en un inofensivo cliché (Garnier 2012). Parece que el derecho a la ciudad ha caído en una jaula de oro, con más visibilidad que nunca (Purcell 2002; Costes 2011), pero con un impacto apenas perceptible y notoriamente limitado a acciones parciales y a reformas urbanísticas (Navas y Makhlouf 2018). Por eso, algunos autores proponen superar la literatura del derecho a la ciudad teorizada hasta ahora (Gray 2018; Uitermark, Nicholls y Loopmans 2012).

Sin embargo, sorteando la perniciosa despolitización e institucionalización del concepto (Gerlofs 2020), el derecho a la ciudad es también bandera de movimientos sociales contestatarios que vindican la plena vigencia del término como horizonte de análisis teórico y de acción política radical que permite asumir la ciudad como una creación colectiva e interpelar las lógicas espaciales del capitalismo (Molano Camargo 2016).

A partir del derecho a la ciudad de Henri Lefebvre se propone ampliar el sentido del concepto a través de los Centros Sociales Okupados (CSO) y sus potencialidades como lugares de encuentro, participación y politización. El artículo enfatiza en las prácticas espaciales del derecho a la ciudad. Pese a parecer una redundancia, en la era de la supuesta descorporeización es vital reivindicar el anclaje espacial de los derechos para entender su necesaria dimensión territorial. Con tal de tener una mejor idea de a qué refieren los Centros Sociales Okupados en cuanto espacialidades emancipadoras y horizontes de un derecho a la ciudad real, se analizan dos casos de estudio de la ciudad de Barcelona: La Vaina y Can Masdeu. Finalmente, el texto se cierra con la recapitulación de las ideas y líneas de discusión planteadas.

\section{Repensando el derecho a la ciudad}

Lefebvre (2017) pensaba el derecho a la ciudad como práctica, no como marco normativo, como una lucha que abriera el disfrute de la vida urbana. Lefebvre reconceptualiza la ciudad como sociedad urbana, para la cual reclama una planificación orientada hacia las necesidades sociales. Para ello hace falta una ciencia de la ciudad y una fuerza social y política capaz de poner en marcha estos medios. Frente a un urbanismo (con su ejército de expertos y técnicos) que ejerce la ciencia de un espacio instrumental y funcional al capitalismo y asienta una ideología, que bajo la máscara de una ciencia técnica y neutral, esconde el planeamiento tecnocrático y la lógica de la dominación (Lefebvre 2013), reivindica el habitar como actividad creativa. Lo lúdico, lo simbólico, el deseo, entran en juego contra una estrategia de alienación, cuya razón de ser traslada de la producción de cosas a la producción de espacio y las relaciones sociales en los sistemas capitalistas.

El contexto de la época fue determinante para desencadenar sus reflexiones. Las ciudades europeas, devastadas por la guerra, pasaban por un impulso de reconstrucción 
social y económica, con una fuerte impronta sobre las ciudades. En Francia, estos conllevó procesos de suburbanización y metropolización en los que las propuestas urbanistas de Le Corbusier y el movimiento moderno llevaban la batuta rectora: Grands Ensembles, planificación racionalista, zonificación. Para Lefebvre, este momento, en realidad, urbano realiza la reproducción de las relaciones de producción capitalistas. En su opinión, esta tutela y mando sobre la vida urbana homogeneizaba y segregaba, por lo que había que imaginar otros pivotes para articular la sociedad urbana. Por ello, prefirió dar más importancia al espacio diferencial que al absoluto, a la autogestión antes que al urbanismo dirigido, al usuario por delante de la estructura cosificadora. Lo urbano se perfila así como la ocasión para acceder a la apropiación del espacio, como paso necesario para una emancipación colectiva. Lefebvre se fija en el uso (y en el usuario) y en la cualidad sensible que encierra el habitar (frente a la miseria del hábitat, que se produce y concibe autoritariamente desde arriba), y vehicula su llamado con el concepto-herramienta del derecho a la ciudad.

Por eso, muchas de las rebeliones que tratan de subvertir la ciudad tienden a invocar este derecho a la ciudad. Sin embargo, la excesiva licencia con que se ha utilizado ha hecho que muchas corrientes críticas (desde activistas hasta académicos) hayan abogado por su repolitización como medio para recuperar su potencial transformador (Benach 2017).

Juntamente a este propósito, también se han buscado alternativas que permitan dar continuidad a un sentido radical de entender la ciudad y las relaciones sociales y de poder (Makrygianni y Tsavdaroglou 2015). El derecho a la ciudad es un excelente marco en el que pensar la ciudad, y complementarlo con otras ideas que expliciten las necesidades de articularnos en diversidad puede ayudar a ensanchar ese legado.

Andy Merrifield (2013) por ejemplo, propone cambiar la prioridad política del derecho a la ciudad a las políticas del encuentro ${ }^{1}$. En su opinión, el encuentro puede inspirar otra vía de acción política, pues este se materializa cuando surge una afinidad, cuando se identifica un enemigo común y cuando se forman nociones y colectividades con un campo de acción común. Esta noción de encuentro -que abreva inicialmente de la última etapa de Althusser- alude a cómo las personas pueden pensar y actuar juntas, de por qué se forman colectividades y cómo la solidaridad toma forma y articula lo político. El encuentro, entonces, es la expresión de una pluralidad de participantes (en la línea de la diversidad de Stavrides (2014), de los seres anómicos de Delgado (1999) o la multitud de Hardt y Negri (2004)) que se reúnen en una forma y fórum abiertos, con una estructura dinámica, tomando partido y cuerpo activamente. Estos encuentros, y los espacios que generan, son la alternativa a una cultura de barreras (Stavrides 2007); esa cultura que define la ciudad

\footnotetext{
1 Este es un punto compartido con Lefebvre, pues para él, la configuración de un nuevo derecho a la vida urbana tiene que pasar porque lo urbano sea un lugar de encuentro. De la misma manera, el pensamiento de Merrifield y el de Lefebvre coinciden en la importancia de la centralidad urbana. Para Merrifield la centralidad juega un papel clave: no la centralidad como cualidad de lo céntrico, sino la centralidad que se produce. Por su lado, Lefebvre concibe una centralidad renovada (no la centralidad de los centros de decisión neocapitalista) que condense las relaciones sociales y que convoque a los sujetos al encuentro y al intercambio.
} 
como una aglomeración de enclaves identificadores, autorreferenciados y cerrados sobre sí mismos.

El encuentro nos remite a lo colectivo, a lo que no es uno mismo ni el otro, sino la esfera compartida. En esta línea, es interesante recobrar la dimensión colectiva (y) del encuentro inserta en la llamada al derecho a la ciudad. Para hacer efectiva la ciudad como provisora de espacios colectivos en los que pensar lo social como una compleja, múltiple y plural articulación, se requieren espacios en los que empoderarse, crear, divertirse, expandir y apropiarse de lo urbano.

Sin embargo, el actual contrato social no se establece en base al reconocimiento de una realidad colectiva, sino que privilegia una desafiliación y una interacción (con la sociedad, con el mundo) individual. El vínculo social se ha reformulado, pasando de la lógica de pertenencia a la lógica de conexión (Garcés 2006). Los mecanismos que la modernidad utilizaba para la agregación de los individuos en proyectos mayores eran la ideología o las diversas instituciones (familia, sindicato), y se basaban en la pertenencia. Actualmente hemos pasado a la lógica de la conexión, en la que la integración al cuerpo social se realiza por la capacidad de conexión que tiene cada uno. De modo que pasamos de una relación mediada por instituciones intermedias a una relación individual. Esto afecta profundamente a la experiencia cotidiana de y en la ciudad. La inclusión y participación en el proyecto político urbano ya no se juega en las relaciones que cada persona genere con un grupo (comunidad, clase, organización), sino en las habilidades acumuladas por cada individuo. Ello dificulta enormemente la aprehensión de una experiencia común y de abrirse a la posibilidad de elaborar un pensamiento integrador que abarque las diferentes circunstancias y situaciones que se dan en la ciudad, para así encontrar una explicación compartida.

Por eso, es importante recuperar la dimensión colectiva del derecho a la ciudad y explotarla desde su potencia política. El derecho a la ciudad no puede ser un derecho formal que únicamente se quede en el papel. Al contrario, debe apelar al encuentro y a la apertura de horizontes que cuestionen las actuales relaciones de poder. Los lazos sociales que pautemos entre los miembros de la sociedad definirán las posibilidades futuras.

La cuestión de qué tipo de ciudad queremos no puede estar divorciada de la que plantea qué tipo de lazos sociales, de relaciones con la naturaleza, de estilos de vida, de tecnologías y de valores estéticos deseamos. El derecho a la ciudad es mucho más que la libertad individual de acceder a los recursos urbanos: se trata del derecho a cambiarnos a nosotros mismos cambiando la ciudad. Es, además, un derecho común antes que individual, ya que esta transformación depende inevitablemente del ejercicio de un poder colectivo para remodelar los procesos de urbanización (Harvey 2008)

Por lo tanto, el derecho a la ciudad es ininteligible sin su vertiente colectiva, lo que en los actuales sistemas políticos significa interpelar a lo público, a la esfera de deliberación y de reconocimiento abierto. A su vez, reunir a una colectividad solo es posible si se cuenta con un espacio, ya que es el espacio donde se forjan las relaciones de poder y donde se 
desarrollan las interacciones sociales (Musset 2015). O como diría Lefebvre, no hay relaciones sociales sin espacio ni espacio sin relaciones sociales. En suma, para que un proyecto enraíce y perdure en el tiempo, antes debe perdurar en el espacio.

\section{Espacializando el derecho a la ciudad a través de los CSOs}

O de nuevo: trata de imaginar, con la mayor precisión posible, bajo la red de calles, el entramado de cloacas, las líneas de metro, la invisible proliferación subterránea de conductos (electricidad, gas, líneas telefónicas, redes de agua, tubos de correo expreso) sin la cual no habría vida en la superficie.

(Perec 1999)

Para los resortes del poder que actúan en los aparentemente etéreos terrenos del imaginario cultural, las ordenanzas municipales o las políticas empresariales, la territorialidad es el imperativo para hacerse presentes. Los conceptos como poder, libertad o participación, pese a su abstracción, necesitan asentarse en un territorio concreto para hacerse valer, perpetuarse y, simplemente, existir. Esos mismos resortes concurren en las dinámicas globales derivadas de la nueva fase de mundialización capitalista y afectan directamente a las ciudades (Pradilla Cobos 2009). Ante una competición a nivel planetario en el que el espacio se vuelve resbaladizo, las interacciones localizadas y el conocimiento contextual adquieren gran importancia (Paba y Perrone 2017). De hecho, cuanto mayor alcance y prospección tienen las ciudades, la posibilidad de generar fricción para las inversiones, aumenta, ya que las ciudades y los diferentes territorios deben presentarse como atractivas. Los poderes político-económicos no gravitan en levitación alrededor del globo terráqueo (Garnier 2006). Por contra, necesitan centros de comandamiento, núcleos acondicionados y un equipo humano especializado en organizar y gestionar.

Sin embargo, la lucha por el derecho a la ciudad es en contra de aquellos que ya tienen un derecho privativo y exclusivo de apropiarse de la ciudad y por una ciudad más democrática y accesible que incluya política y simbólicamente a los desfavorecidos, subalternos y excluidos (de Souza 2010; Attoh 2011; Purcell 2013). Para imaginar esta ciudad alternativa es imprescindible dar lugar a esta otra ciudad, y en consecuencia, dotarlo de materialidad, ocupar (u okupar, en este caso) un espacio. Así, uno de los aspectos básicos para cualquier movimiento es, por un lado, la construcción desde la base de contrainstituciones y de áreas seguras en las que nuestro día a día, nuestra cultura y nuestro arte puedan romper la hegemonía del sistema, y por otro, organizar confrontaciones con la dominación de la élite (Steen, Katzeff y Hoogenhuijze 2014).

Los ateneos de la primera mitad del siglo XX cobijaron sociabilidades políticas alternativas y permitieron la expresión de diferentes culturas políticas del momento, albergando también funciones instructivas y formativas y de divulgación cultural y política (Navarro 2016). Del mismo modo, hoy día resulta fundamental disponer de algunas 
localizaciones en el territorio (asambleas populares, Centros Sociales -okupados o no-, librerías) desde los que vertebrar iniciativas sociales, culturales, económicas o políticas y facilitarla transformación social.

Estos anclajes se pueden conceptualizar como una infraestructura que crea una red mínimamente estable para dar apoyo a diferentes organizaciones y proyectos sociopolíticos y culturales. La creación de una infraestructura urbana radical (Vasudevan 2017, 172) no solo es importante en su dimensión espacial, sino que es fundamental para que florezcan nuevas dinámicas de lucha y nuevas generaciones de luchadores. Una idea o un imaginario político puede tener éxito o fallar, pero es impotente sin un soporte físico (Dikeç y Swyngedouw 2017).

Existen estudios sobre cómo el desarrollo de infraestructuras urbanas, teniendo en cuenta su naturaleza sociotécnica (Amin 2014), pueden mejorar el ambiente en contextos de recursos materiales escasos y/u hostilidad estatal, haciendo que los más desfavorecidos puedan ejercer sus capacidades creativas para intervenir lo urbano (McFarlane 2008; Koster y Nuijten 2016). De hecho, las crisis económicas y su correspondiente crisis de reproducción social provocan que diferentes grupos sociales se vean obligados a encontrar nuevas formas de satisfacer sus necesidades y deseos colectivos mediante el intercambio, la ayuda mutua y la colaboración. El caso griego demuestra cómo, tras la crisis del 2008, los movimientos sociales antagónicos adquirieron características constitutivas, al expandirse a prácticas reproductivas, desplegando bienes comunes y estructuras de economía social y solidaria (Bekridaki y Broumas 2017). Lo mismo ocurre con las llamadas 'prácticas económicas alternativas' (Méndez 2015; Gil Álvarez 2017), que desempeñan el papel de nodos territoriales de la red de economía alternativa (locales en los cuales intercambiar productos, reunirse, conocer miembros de la red, etc.). Este tipo de infraestructuras urbanas son fundamentales para propiciar que el derecho a la ciudad pase del plano formal al real, ya que incitan a la re-unión y movilización colectivas, y en último término, a tomar partido y politizarse.

En esta línea, los Centros Sociales $0_{\text {kupados}}^{2}$ son infraestructuras que apelan al encuentro, pues fue justamente esa la innovación que introdujeron en el movimiento por la okupación: la proyección pública. De esta manera, actúan como paraguas para los movimientos sociales, garantizando que puedan sobrevivir, darse a conocer y reproducirse.

Los CSOs forman parte del movimiento de okupación, por lo que es conveniente contextualizarlos dentro de su génesis más amplio. El movimiento de okupación abarca diferentes ámbitos y comprende diversas estrategias, aborda amplias problemáticas y acoge variados colectivos y personas con trayectorias dispares. Incluso existe un debate sobre si considerarlo 'un solo' movimiento social (Martínez 2004). Por lo tanto, hablar de okupación es adentrarse en un universo extremadamente complejo que es hoy más heterogéneo que nunca (Martínez y Cattaneo 2014; Cattaneo y Tudela 2014). Por eso, conviene huir tanto de

2 Aquí se utilizará genéricamente el acrónimo CSO, aunque también se engloban bajo el término de Centros Sociales Okupados y Autogestionados (CSOA). 
la visión simplificadora de un okupa homogéneo (que la mayoría de veces se identifica con un activista masculino), como de un bloque monolítico que actúa unificado y unánimemente.

Sin embargo, en cualquiera de sus formas, su capacidad antagonista se destaca claramente, y con el tiempo ha ido adquiriendo algunos elementos característicos que lo identifican: la denuncia política anticapitalista, una radical autonomía, la filosofía ecologista del 'hazlo-tú-mismo', la creación de espacios socioculturales críticos y de medios de comunicación alternativos. El movimiento okupa se comenzó a gestarse en la década de los años 60 y 70, en múltiples iniciativas en el continente europeo, compuesto por jóvenes descontentos con la situación sociopolítica, críticos con el sistema económico e insatisfechos con el reducido horizonte cultural. En este contexto, el movimiento surgió de la convergencia del movimiento por la vivienda, el movimiento juvenil y las tendencias contraculturales del momento.

En el caso específico de Barcelona, el movimiento de okupación inició en la década de los 80 con los jóvenes que necesitaban espacios musicales (Fernández Gómez 2010). El movimiento, tardío respecto a Europa por la represión y el retroceso cultural que supuso la dictadura, sirvió de intercambio generacional entre los libertarios que traían la herencia de la Guerra Civil y los jóvenes descontentos que no querían adaptarse a los cauces institucionales de la nueva democracia. En aquellos años (final de la dictadura, emergencia de luchas vecinales y obreras, expansión del asociacionismo, etc.) hubo una recuperación de lo contracultural, de las políticas radicales y de un antifascismo revolucionario herencia del 36 (Tutor Anton 2020).

La emergencia del movimiento okupa, que tuvo en Barcelona uno de sus epicentros más importantes del Estado, coincide al igual que en otras ciudades con la crisis del movimiento vecinal (Martínez 2007). Hasta entonces, la disidencia estaba capitalizada fundamentalmente por partidos políticos, asociaciones de vecinos y sindicatos, pero una vez acatada la Transición, los partidos se limitaron a la acción parlamentaria y electoral, los sindicatos a protestas puntuales y las Asociaciones de Vecinos entraron en declive en favor de los movimientos sociales, que pasan a ser los nuevos portadores del malestar. Éstos necesitan espacios donde reunirse y comienzan a okupar, públicamente (Gutiérrez Barbarrusa 2004). Un ejemplo que perdura hasta hoy (y último remanente de esas ocupaciones vecinales de finales de los 70) es el Ateneu Popular de Nou Barris, un centro cultural de control directo y autogestionado - actualmente cedido por el Ayuntamientoque el vecindario recuperó para el barrio.

Por lo tanto, el movimiento de okupación barcelonés, ya desde su comienzos, se abrió y se nutrió de otros actores que le daban a la ciudad la fama de Rosa de Foc. Estas alianzas continuaron con fuerza a partir de 1996 (en lo que algunos autores llaman su era dorada (Cattaneo y Tudela 2014)), con entrecruzamientos con protestas antiglobalización, contra la guerra o, más recientemente, con el 15M. La versatilidad del movimiento indica que no es un fenómeno estanco y que, en parte, es producto de su época.

Estas influencias dispares hacen que a pesar de compartir un mismo método, los posicionamientos y análisis de coyunturas diverjan dentro del movimiento. Una de las 
divisiones más notables y recurrentes remite a la esencia de la práctica de okupar. La posición más extendida es aquella que toma la okupación como un fin en sí mismo, es decir, el desafío que supone contra la propiedad privada y las relaciones sociales y de producción capitalista. Sin embargo, con los años se volvió habitual modular este principio y utilizar la okupación instrumentalmente para conseguir algún fin determinado; entender la okupación como medio para. El debate sobre la deriva reformista, la cooptación o la institucionalización de algunas experiencias de okupación ha tenido un seguimiento y eco en diversas publicaciones (Pruijt 2003; González 2004; Martínez 2010b; Pruijt y Roggeband 2014). En el Estado español también encontramos okupaciones que de una u otra manera convergieron con partidos y otros espacios institucionales, como el Patio Maravillas en Madrid. En Barcelona el Espai Social Magdalenes o La Kasa de la Muntanya entraron en una dinámica de negociación y legalización, causando importantes debates y fracturas en el seno del movimiento (González, Cortina-Oriol y Aguilera 2019). Tanto unos como otros ensayan sus propias vías para practicar el derecho a la ciudad, aunque los procesos de legalización les restan autonomía de manera notoria. Esta pluralidad de perspectivas se reproduce en el universo de los $\mathrm{CSOs}^{3}$. La llegada de Barcelona en Comú al gobierno municipal en 2015 replanteó la relación entre los espacios okupados y las autoridades municipales, de modo que se incrementaron las propuestas de regularización (uno de los estudios de caso y uno de los proyectos de okupación más longevo y emblemático de la ciudad, Can Masdeu, está inmersa en esta disyuntiva).

En síntesis, los Centros Sociales Okupados son edificios que uno o varios colectivos han tomado y abierto, en contra del criterio de la propiedad (generalmente una inmobiliaria, un banco o alguna institución pública) que lo mantenía sellado e inaccesible. Estos espacios comenzaron su andadura vinculados a la okupación, que animó las múltiples actividades políticas y personales del movimiento alternativo y de otros movimientos sociales afines (Martínez 2003). Su nacimiento viene marcado por la reorientación del movimiento de okupación hacia una mayor proyección exterior y un mayor grado de implicación en las problemáticas urbanas, que comenzó a producirse en Italia a finales de los años 60, influenciado por el movimiento autónomo y libertario. Por eso, pese a que se coordinen entre sí, su organización se basa en una descentralización radical (González, Martínez y Barranco 2018). Los CSOs suponen la apertura consciente del movimiento a la ciudad y a la sociedad, en cuanto se focalizan en un proyecto público (Mudu 2004; Ruggiero 2000), que transmite la reivindicación, abierta, de una iniciativa autogestionada ${ }^{4}$ que desarrolla una labor de crítica en lo político y en lo cultural. A diferencia de las okupaciones de vivienda o las okupaciones de fábricas, que por lo general se llevan a cabo para satisfacer una necesidad material e inmediata, la fundación de CSOs es también el fruto de una politización volitiva y

3 Como referencia para vislumbrar este gran abanico, solo hay que cotejar los datos que muestran que entre 1984 y 2013 se crearon alrededor de 370 CSOs (Cattaneo 2014).

4 La práctica de la autogestión territorial es un modo de llenar de contenido el derecho a la ciudad, en cuanto se apropia de lo urbano sin esperar a que instituciones externas otorguen ese derecho (Gray 2018). Por eso, para Lefebvre la lucha por la autogestión es la lucha por la democracia, porque les permite gestionar la ciudad por sí mismos (Purcell 2013) y de transformar la forma en que producimos y usamos el espacio. 
cuya finalidad es el propio accionar transformador. Así, los CSOs cumplen dos funciones básicas: ofrecer un recurso público para reuniones, ocio y mantener el hilo y el intercambio entre diferentes activistas y dotar de visibilidad al movimiento y otros colectivos (Martínez 2011).

Los CSOs proveen de infraestructuras a las ideas y ayudan a que se materialicen, que arraiguen, pues quizá de otro modo, sin un punto de reunión e intercambio, la idea no podría haber pasado de las conciencias individuales y crear un proyecto colectivo comúnmente abonado y abordado. Precisamente es gracias a estas aportaciones y visiones de diferentes individualidades, de diferentes cosas que no son uno mismo, que se desempeña la necesaria externalidad recíproca (yo soy tu exterioridad, revisito tu idea, la complemento o la retoco, y tú eres la mía) que toda idea necesita para madurar y fructificar.

Un CSO puede ser la mejor plataforma local para agregar personas y colectivos con sensibilidades afines, para hacer visibles temas y luchas sociales de los márgenes censuradas en los mass media, y para introducir a nuevos activistas en prácticas de desobediencia civil y social (Martínez 2007). Los movimientos sociales tienen un gran nomadismo, y por eso es necesaria la conformación de artefactos político-espaciales que permitan continuar la lucha. Al mismo tiempo, posibilita que esta lucha tenga un núcleo del que emana una cohesión como grupo y como horizonte y abre un espacio para condensar y estabilizar vínculos. Así como un acontecimiento temporal puede poner en 'circulación' conocimientos mutuos a través del magnetismo del momento, un acontecimiento espacial como el Centro Social Okupado pone en comunicación a diversas personas y puede engancharlas a un activismo político-social a través de la permanencia de estar en un lugar.

De esta manera, un Centro Social Okupado podría funcionar como una interzona (Bey 2014), que permite crear nuevas historias y secuencias. Algo parecido a lo que los municipios rebeldes zapatistas consiguieron en el sureste mexicano: conectar territorialidades dentro de un marco transformador. En tanto que infraestructura indispensable para otros movimientos urbanos, los CSOs cumplen una tarea de articulación de las redes sociales locales (González, Martínez y Barranco 2018). Asimismo, el CSO imagina relaciones sociales y de poder alternativas, a partir de la crítica a los sistemas de dominación, pero también trayendo los valores utópicos a lo cotidiano (Diz 2017). Gracias a esta perspectiva, la ciudad puede pasar a ser co-producida a través de canales formales e informales (Mahabir, Crooks, Croitoru y Agouris 2016) que no se limitan únicamente a la esfera abstracta política, sino que inciden directamente a un nivel espacial, que cambia la topología de la ciudad (crean nuevos espacios que crean nuevas relaciones que impactan en el tejido urbano y en el día a día de la población). Los CSOs impactan así en la sociabilidad, ya que el empoderamiento y la eventual politización brotan directamente de la experiencia personal. La politización también se refiere a la democratización de las posibilidades de politización.

Y, a la vez, en algún barrio, el antiguo local del economato se transforma en un nuevo centro social ocupado, donde gentes que están hartas, que tienen ideas, que siguen 
luchando, que también están fuera, que no se creen el cuento, ponen en práctica otras formas de estar, de hacer, de consumir (Carabancheleando 2017, 88)

Por tanto, el derecho a crear infraestructura entronca directamente con el derecho a la ciudad, a crear y co-producir ciudad, a 'prototipar' la ciudad en un plano conceptual, técnico o político (Corsín 2014).

Así, en tanto lugares de encuentro y espacios de socialización, son marcos inmejorables para estudiar nuevas relaciones sociales y nuevos accesos a la ciudad. En los CSOs la inquietud por la insatisfacción del concepto de derecho a la ciudad se afronta de manera disruptiva, dando lugar (produciendo lugar, pues es evidente la importancia del espacio para formalizar poderes) a espacialidades emancipadoras (Stavrides 2016). Estas espacialidades emprenden el camino de agenciar la acción de los movimientos sociales con el espacio y el lugar (Oslender 2002) y de tentar los cimientos de otro tipo de sociedad.

Ward (2013) afirmaba que una sociedad diferente ya estaba aquí, y que procrastinar la realización transformadora a la espera de un cambio totalizador es mistificador en cuanto desactiva las posibilidades del presente. Un presente en el que ya existen espacios desde donde se puede desarrollar una secuencia política insurgente, en el sentido de espacializar una concepción igualitaria de la emancipación (Lebuhn 2017). Los CSOs abren estas posibilidades y explotan las potencialidades del capital humano del presente, que la mayoría de veces urde el cedazo de unos nuevos equilibrios de poder (descentralizados, sin dominación y con una solidaridad y cooperación horizontales).

En definitiva, espacializar también quiere decir acercar, hacerlo visible, próximo. Los Centros Sociales permiten tomar el pulso de lo cotidiano y tornar cotidiano aquello que se nos escamotea. Si el proceso productivo se desprende del trabajador por medio del salario, que establece la relación con el trabajo en función de un determinado tiempo a cambio de una determinada cantidad de capital, el Centro Social Okupado organiza actividades formativas y también seminarios políticos que desmontan la ideología o la moral del trabajo capitalista. Si el proceso político se sustrae de la conversación del bar o del metro porque es una ciencia de expertos profesionales, el CSO abre un ciclo de charlas en las que cuestionan algunas asunciones y consensos básicos (la utilidad de las instituciones, quién detenta el poder efectivo, etc.). Si se nos invita a contemporizar pasivamente con un consumo cultural que adocena, el Centro Social Okupado invita a la asistencia de un taller literario, una obra de teatro o una efervescente sesión de cabaret. Si el proceso social se mistifica, su entendimiento, su gestión, por una multitud de mediadores técnicos ininteligibles, el CSO explora y difunde el derecho a la ciudad insurgente o propone, en el terreno de la colectividad y del encuentro compartido, un grupo de cuidados.

\section{Dos CSOs, dos caminos... un objetivo común}

Barcelona guarda en su seno una vibrante actividad cultural y política. La creación de Centros Sociales Okupados se comprende como causa y consecuencia de esta atmósfera. Desde su aparición, los CSOs han desarrollado alternativas de ocio, espacios de agitación cultural y experimentaciones de procesos asamblearios y de democracia directa (González, 
Martínez y Barranco 2018). En esta investigación se analizan dos de estos lugares, La Vaina y Can Masdeu.

La metodología utilizada para adentrarse en los dos casos fue cualitativa. Para el trabajo de campo, realizado entre los años 2015 y 2017, se llevó a cabo una observación (participante y no participante) y se recabaron testimonios de diferentes personas vinculadas a los CSOs, clasificando las entrevistas según grupos de interés. Así, se decidió agrupar las personas según el tipo de interacción con el espacio, dando como resultado tres grupos: Habitantes (que conforman el proyecto), Participantes y Visitantes (que se acercan con cierta regularidad al espacio) y Vecinos (las personas que vivían en el barrio). Para los dos primeros se hicieron 15 entrevistas semiestructuradas y 30 cuestionarios para los vecinos. El perfil de los entrevistados varió, ya que en Can Masdeu el promedio de edad era entre 40 y 50 años y en La Vaina se situaba en el tramo de edad entre 20 y 30 años. En ambos casos se entrevistó tanto a hombres como mujeres. Las entrevistas fueron grabadas, tuvieron una duración media de una hora y se realizaron en catalán y en castellano, en función de la preferencia del entrevistado. Para transcribir y analizar la información se optó por utilizar códigos, que facilitan sintetizar el contenido, agruparlo por temáticas (tanto previas como las que surgieron durante las entrevistas) y extraer las citas que procedan. De igual modo, y para garantizar la anonimidad de los entrevistados, se utilizó una codificación para identificar a los informantes. Este se hizo en función de género, la edad (Joven -'J'- (16-35), Adulto -'A'-, (35-60), Adulto Mayor -'AM-, (60 en adelante)), el tipo de entrevista ('H' para Habitante, 'P' para Participantes o Visitantes y 'V' para Vecinos), el lugar y el número de entrevista. Por ejemplo, para un hombre adulto habitante de Can Masdeu el código sería HAHCmd1 o para una mujer joven participante o visitante de La Vaina, este otro MJPLv1.

La elección de los dos CSOs se hizo por la facilidad que tuvo el investigador para acercarse a estos espacios y hablar con sus habitantes y participantes, que pueden llegar a ser herméticos y recelar de quien pregunta. Además, ambos casos representan espacios de encuentro en el sentido en que se utiliza el término a lo largo del artículo, pues abren edificios y espacios en lugares en los que no hay alternativas parecidas. Para orientar el trabajo, se tomaron investigaciones similares que trataron la apertura de Centros Sociales como espacios de encuentro y espacios públicos autogestionados, como la Eskalera Karakola (González y Araiza 2016; Marinas Sánchez 2004), espacios okupados que realizaban prácticas contraculturales (Moore y Smart 2015) o la experiencia de edificios y solares abandonados que se okupaban por una estrategia transversal y vecinal de reactivación de la vida barrial, como en el caso del Ágora Juan Andrés (Astudillo Salazar 2019) o el Banc Expropiat (Dee y Rodrigues 2014).

Pese a la disparidad de la trayectoria y la composición de La Vaina y Can Masdeu, en ambos casos encontramos elementos que concuerdan con acciones para recuperar el contenido del concepto del derecho a la ciudad. Como comprobaremos más adelante, los dos espacios guardan una similitud en cuanto actúan de fijadores espaciales de alternativas y 
creadoras de una red de contestación ${ }^{5}$ crítica a las diferentes políticas públicas y privadas que impactan en la vivencia de la ciudad.

En efecto, aunque cada CSO es un mundo en sí mismo, todos tienen un objetivo compartido: autogestionarse y autodeterminarse la vida (en la ciudad). Al okupar un espacio y abrirlo a la sociedad, no sólo se sustraen inmuebles abandonados de las lógicas especulativas, sino que se genera el principal recurso para llevar adelante la autogestión colectiva y reanudar otras formas de relacionarnos, lo que indica la necesidad y centralidad del espacio (Martínez 2010a).

Otra de las cuestiones en que las dos experiencias vienen de acuerdo es en que debe existir una proactividad para que la iniciativa prospere. Hablar de proactividad es hablar de participación, que significa que pensar la alternativa es ejercer la alternativa. La alternativa o la oposición a lo que actualmente existe no nace por generación espontánea, sino de una generación política consciente, que conquista lo político y lo hace parte de su práctica. Estas prácticas sociales y espaciales niegan que otras personas que no seamos nosotros tomen las riendas de la gestión de los asuntos que nos conciernen. Este pensamiento que se entronca con la filosofía del 'hazlo-tú-mismo' supone tomar el control sobre la producción (material y simbólica) de la ciudad (Iveson 2013).

Asimismo, La Vaina y Can Masdeu pueden representar una cierta idea de comunidad (la naturaleza comunitaria está mucho más presente en Can Masdeu, que incluso se autonombra así), muy unida a la colectividad ${ }^{6}$ que dio origen a estas espacialidades. El diseño colectivo, la transformación espacial y la corresponsabilidad en el mantenimiento de un espacio fortalecen los vínculos comunitarios de las personas implicadas (del Viso, Fernández Casadevante y Morán 2017) y en correspondencia, la cultura de lo común puede crear prácticas colectivas (García Puchades y Miquel 2016), y viceversa. La comunidad, concepto controvertido y polisémico, en esta investigación se emplea como complementario a la colectividad. Pese a que lo colectivo pueda tener una lógica asociativa y lo comunitario una connotación premoderna y de afiliación primaria ligada a lo emotivo o familiar, hoy en día las fronteras entre ambas concepciones se han disuelto. Uno de los problemas de la sociedad moderna, de hecho, es encontrar un nuevo principio de articulación comunitaria que parta del individuo y que no se apoye exclusivamente en la tradición para su reproducción (Gurrutxaga 1991). Estas nuevas dimensiones comunitarias están ligadas a la pluralización de la vida social y sus máximos exponentes se encuentran en la vida urbana. En este contexto se encaminan las experiencias de La Vaina y Can Masdeu, en la formación de comunidades y espacialidades de vínculos solidarios y no únicamente instrumentales y arreglo a fines. Su autogestión colectiva puede llevar a determinadas situaciones de autogestión comunitaria, aunque como indica una de las habitantes de Can Masdeu, hacer

5 En el caso de La Vaina, el espacio pudo ser recuperado gracias a la ayuda y la experiencia de otro CSO, La Gordíssima. El intercambio de conocimiento entre diferentes activistas demuestra el estímulo colectivo que representan estos espacios, tejedores de una red que conecta afinidades e inquietudes y difunde (espacialmente) la práctica de otra ciudad.

6 En inglés se utiliza la misma palabra, 'community' 
cosas en común no siempre significa creerte parte de una comunidad. En general, ambas experiencias se pueden interpretar bajo el marco de comunidades intencionales (Schehr 1997): un grupo de personas que han elegido vivir y/o trabajar juntos en pos de un objetivo común, más allá de la tradición, las relaciones personales o los lazos familiares (Sargisson 2007).

\title{
La Vall de Can Masdeu
}

\author{
Defendemos lo público autogestionado y socializado \\ desde abajo. Que es la antítesis de lo público \\ estatalizado \\ (Carlos Taibo)
}

Can Masdeu está enclavado en la sierra de Collserola a unos 15 minutos a pie del barrio de Canyelles (distrito de Nou Barris). El edificio es una antigua masia que data del siglo XVII y se encuentra en uno de los valles no urbanizados -a diferencia de los colindantes- del lado barcelonés de Collserola, antiguamente conocido como la Vall de Sant Genís. Desde 1906 hasta 1955 funcionó como leprosería del Hospital de Sant Pau; después fue abandonada 47 años. Actualmente pertenece a la Fundación Hospital de Sant Pau, que está participada por el Obispado de Barcelona, la Generalitat y el Ayuntamiento (tríada conocida como MIA, la Muy Ilustre Administración).

El edificio fue okupado en diciembre de 2001; rehabilitado como vivienda y Centro Social, está en activo desde entonces. Uno de los hitos fundacionales fue la tenaz e imaginativa resistencia (se colgaron de la fachada y se suspendieron en el vacío en unos travesaños) que llevaron los okupantes a cabo durante tres días (entre finales de abril y principios de mayo de 2002). La victoria moral -la reivindicación de un modo alternativo de vida y de apropiación de la tierra y edificios abandonados- y física -lucharon hasta el extremo por el derecho a habitar la casa- marcaron positivamente el devenir del proyecto e insufló fuerzas tanto al movimiento como al colectivo de la casa y a muchos vecinos que apoyaron la resistencia. Hoy en día se sigue conmemorando este hecho con la fiesta de la resistencia que anualmente convoca a centenares de personas durante todo el día y parte de la noche en las laderas de Can Masdeu.

Algunas de las peculiaridades de esta okupación son la dilatada trayectoria del proyecto (que tiene cerca de 20 años), lo cual influye en la consolidación y fortaleza del proyecto y en la composición de sus habitantes; ser un espacio intergeneracional y que la franja de edad sea, de promedio, más elevada que otros CSOs y el hecho de que Can Masdeu 
sea vivienda de las personas que forman el proyecto. Finalmente, otra cuestión que contrasta con otros CSOs, es la privilegiada situación que tiene sobre la ciudad de Barcelona, pues se sitúa fuera del perímetro urbano y tiene tierras cultivables. De hecho, Can Masdeu se llama en realidad La Vall de Can Masdeu, lo que nos evoca la importancia de la tierra y el entorno en su proyecto. La cuestión de la tierra (los huertos, el terreno, el paisaje) es la que mayor disparidad crea respecto otros CSOs, ya que es un atractivo muy peculiar del que pocos disponen. Can Masdeu interacciona muy estrechamente con la ciudad. La ciudad es el telón de fondo y el que provee de insumos, pero también es parte indisoluble del proyecto, sin el cual el actual planteamiento no sería viable.

la ciudad se ve como una fuente de recursos, que más o menos permite crear el imaginario hippie, sin connotaciones, imaginario juvenil de irnos a un caserío a vivir, esto te da la posibilidad de vivir; en el campo y al mismo tiempo beneficiarte de dos cosas, una es que todas las prestaciones económicas que surgen de la ciudad, aquí todos tenemos enlaces con la ciudad" (HAHCmd2)

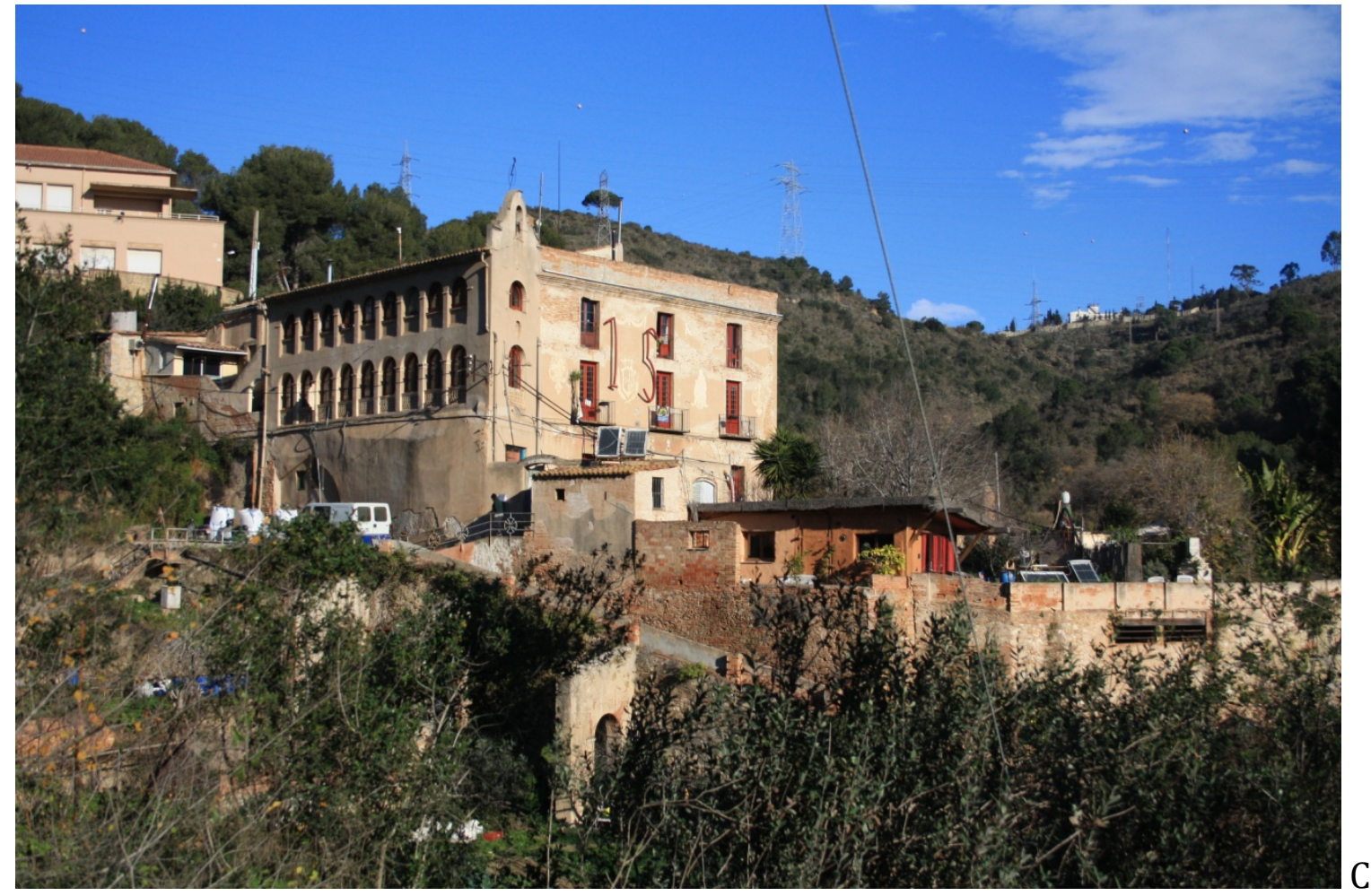

Masdeu

Fuente: Aritz Tutor Anton

Can Masdeu, considerada como espacialidad emancipadora que experimenta un derecho a la ciudad efectivo, activa dinámicas conducentes a un control y soberanías integrales sobre la propia vida y el entorno. El mismo edificio y el valle son, según admiten ellos mismos, un ejemplo de esta filosofía, pues están en permanente construcción. Gracias a una apropiación del tiempo y del terreno, así como las ganas de desarrollar las habilidades necesarias, Can Masdeu se ha ido configurando en un entorno en el que practicar el hazlotú-mismo a todos los niveles, desde los cuidados -la comida se prepara rotatoriamente- 
hasta obras domésticas y de infraestructuras. No en vano, uno de los componentes centrales del proyecto es la voluntad de que todas las personas puedan aunar la esfera intelectual y manual, englobada a su vez en la esfera emocional.

En este sentido, la Comunidad ${ }^{7}$ siempre ha contado con la ayuda y solidaridad de personas y colectivos del exterior. Como reza en su web, "si no es acompañados, no es nuestra revolución". La Comunidad siempre ha tenido claro que el apoyo es clave para el proyecto, tanto para su mantenimiento y reproducción, como para la legitimidad y para la coherencia con el mundo que quieren construir. La Vall se ha ganado a pulso la consideración de un equipamiento (social, agroforestal) más del distrito. Como una de la participante MAMPCmd1 expone,

No fue una okupación de una gente que okupa para ellas, sino que fue una okupación también ligado con toda la cuestión social del barrio. Una okupación abierta al barrio

Tal como afirman, en concordancia con la sentencia que da entrada al texto, reivindican la defensa agroecológica de Collserola y una gestión pública del valle, pero entendiendo lo público sobre todo como recuperación de los comunes, es decir, espacios y recursos sustraídos a la lógica mercantil y autogestionados por la colectividad.

Asimismo, la Comunidad siempre se ha volcado con las luchas de la ciudad (apoyando otros Centros Sociales -Okupados o no- y movimientos sociales) y con luchas similares alrededor del mundo y del continente ${ }^{8}$ (ejemplos son la implicación en la lucha contra el pantano de Itoiz, las luchas altermundistas y contra la Europa del Capital, cómo se involucran en respaldar y promover okupaciones rurales o las luchas zapatistas). No obstante, esta orientación hacia el exterior ha cambiado en los últimos años:

antes tuvimos más contacto con los centros okupas y los Centros Sociales (...) cuando empezamos el proyecto no teníamos niños, no teníamos trabajos. Era Can Masdeu y la red de los otros okupas. Ahora que cada uno tiene su vida y menos tiempo para involucrarse, la gente tiene menos tiempo para dedicar a cosas de fuera" (MAHCmd1)

Can Masdeu engloba a cinco proyectos. La Comunidad (los habitantes de la casa, una comunidad de vida y un colectivo político) es el núcleo central que permite la articulación de los otros cuatro 9 : el Punto de Interacción de Collserola (PIC), la Educación Agroecológica, Permacultura Barcelona y los Huertos Comunitarios. La experiencia del PIC y de los Huertos Comunitarios son los más interesantes, porque son los que más personas atraen y mayor interacción y momentos de socialización generan.

El Punt d'Interacció de Collserola (PIC) es propiamente el Centro Social de La Vall, que gestiona la Comunidad pero cede el espacio a organizaciones afines que quieran

7 Así se refieren a sí mismos. La Comunidad son las personas que viven permanentemente en Can Masdeu.

8 Todo ello ha comportado que Can Masdeu sea, al igual que, por ejemplo, Christiania (Coppola y Vanolo 2015), un nodo central en la red internacional de activismo y contracultura.

${ }^{9}$ El proyecto tiene una página web (canmasdeu.net) con información muy detallada y actualizada, otra muestra de su deseo de abrirse transparentemente y comunicar sus motivaciones. 
difundir su proyecto o ideas. Suele abrirse los domingos y cobija una amplia gama de talleres, actividades, charlas y actuaciones artísticas (jam sessions, talleres, manualidades, (acro)yoga, corrientes milenaristas o new age; en general se prioriza lo político reivindicativo y la espiritualidad). El PIC incluye la tienda gratis, basada en el trueque, una biblioteca bien surtida de pensamiento crítico y ecologista, el RurBar, y la oficina Rurbana, un recurso para quienes quieran empezar una nueva vida en el campo (consejos, mapas de casas rurales vacías, diversos proyectos agroecológicos, banco de semillas).

A su vez, los Huertos Comunitarios es el proyecto más popular y el que más conecta la casa con su entorno social. Se trata de un proyecto autónomo que llevan a cabo un centenar de personas (entre participantes y habitantes de la casa), cultivando pequeños huertos -35 parcelas en total-. Como cuenta HAHCmd1,

\begin{abstract}
El hecho de que los vecinos se han implicado porque también se han beneficiado de esta okupación, esta okupación ha beneficiado a mucha más gente de la que vive aquí y sigue beneficiando a mucha más gente de la que vive aquí. Porque el hecho de que no esté en la ciudad también es un tema importante, ha permitido que no se okupe solamente el edificio que es lo que suele pasar en las okupaciones urbanas, sino que se ocupe también la finca alrededor, el espacio y todo eso, la suma de todo eso es Can Masdeu y cuando okupamos toda la tierra la idea era decir ¿qué hacemos con tanta tierra? Fueron precisamente muchos de los vecinos los que empezaron a demandar en el sentido de preguntarnos: -¿Vosotros qué vais a hacer con la tierra? ¿No me daríais un huertecillo, un cacho para que yo haga mi huerto?- y así fue cómo surgió el tema, en este sentido fue muy orgánico.
\end{abstract}

Se define como movimiento de reapropiación vecinal de la tierra, ya que el proyecto, pese a su diversidad, integra mayoritariamente a gente mayor del barrio (muchos inmigrantes gallegos, andaluces y extremeños de origen rural). La gente del barrio se volcó con la idea de hacer huertos y que incipientemente ya usaban antes de la okupación. Las bases del proyecto son:

- el componente intergeneracional;

- el intercultural, entre la cultura alternativa y la cultura tradicional;

- la participación en los engranajes de la casa;

- la generación de un espacio de relación y de interacción social comunitaria en el barrio en torno a la excusa de la agricultura, hacer de 'puerta' a la agricultura ecológica en un entorno urbano;

- empoderamiento a la hora de gestionar espacios naturales próximos a la ciudad de Barcelona. Concienciar de la necesidad de defender el valle y Collserola como un espacio amenazado por las políticas urbanísticas;

- recuperar el uso agrícola tradicional de la finca;

implicación en el conjunto del proyecto de Can Masdeu a través de la organización asamblearia (y el aprendizaje de las dinámicas asamblearias, desconocidas para la mayoría) y la toma de compromisos y responsabilidades 


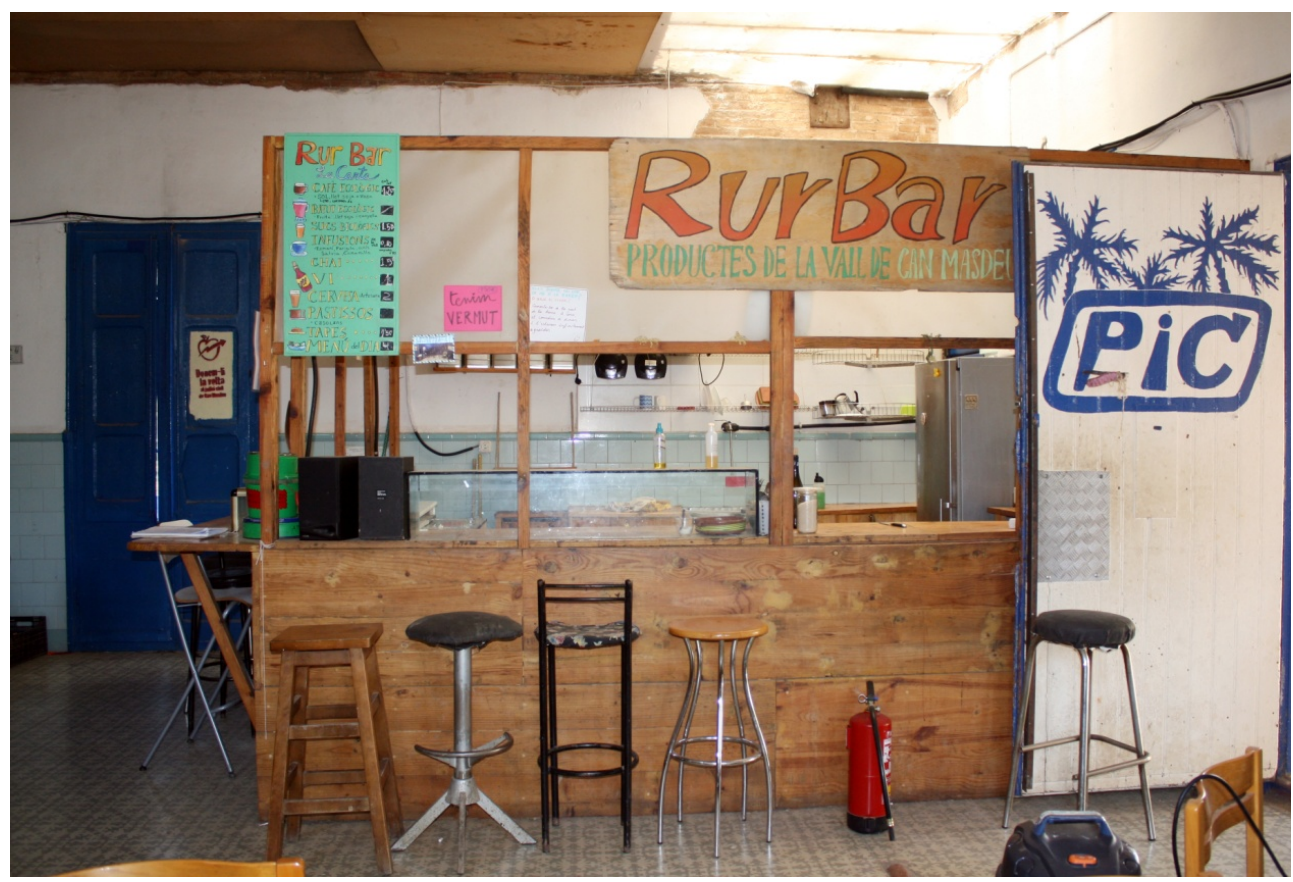

El RurBar

Fuente:: Julia Stollenwerk

La participación en este tipo de lógicas empodera a los involucrados y se liga directamente con el derecho a la ciudad, ya que en su corazón se encuentra el derecho a participar en la creación de su futuro (Chatterton 2010). Así, Can Masdeu contrasta con otros proyectos ligados a la tierra, en las cuales las personas sólo van a trabajar el huerto, sin vincularse vitalmente con el espacio. Tal como señala HAPCmd4, "en otros proyectos un conserje se encarga de cerrar y abrir el espacio", siendo una experiencia mucho más impersonal y menos comprometida. La singularidad de Can Masdeu es la libertad de apropiarte del tiempo y del espacio, la sensación placentera que puede dar una simple higuera:

meterte en una sala muy bonita, muy bien hecha, con unas sillas perfectas y un alumbrado tal a estar debajo de la higuera que estás ahí y te cae un higo encima... La verdad, jno tiene color! (MAMPCmd1)

Por lo tanto, Can Masdeu, sin abandonar su(s) política(s), decide formar parte del entramado sociocultural que construye la ciudad y conformar públicos alternativos y críticos.

\section{CSO La Vaina}

Lo importante no es lo que han hecho de nosotros, sino lo que hacemos con lo que han hecho de nosotros 
Este CSO se encuentra en el barrio de Congrés i els Indians (distrito de Sant Andreu), cuyo desarrollo urbanístico más notorio se llevó a cabo a raíz del Congreso Eucarístico de 1959. El local donde actualmente está el Centro era una sucursal bancaria que permaneció abandonada durante varios años antes de su okupación. A mediados de 2014, un grupo de jóvenes que veían que la periferia de Barcelona no tenía espacios que dieran cabida a sus aspiraciones e inquietudes, okuparon el espacio. Según HJHLv1, "no hay un espacio para jóvenes en el Congrés o por lo menos no un espacio para jóvenes al nivel que quieren los jóvenes del Congrés". El impulso para liberar la sede de un antiguo banco no vino, entonces, por un mero voluntarismo ideológico, sino por unas necesidades que, al no verse satisfechas por los cauces institucionales, fueron reclamadas mediante acción directa. La juventud organizada (en torno a la 'Assemblea de Joves del Congrés') y hastiada, experimentó nuevas vías para apropiarse de su inmediatez material (en este caso proveerse de un local para sus actividades). Tal como relata MJHLv1

cogimos las riendas 3 ó 4 personas de la asamblea de Joves del Congrés y con esta gente empezamos a mirar sitios y vimos que lo más viable era La Caixa de Riera d'Horta que era una Caixa que estaba oculta más o menos, que no daba a una gran calle y que era muy fácil abrirla. Total que la abrimos, no hubo ningún problema para abrirla, nos ayudó La Gordíssima

Esta empenta encaja perfectamente con lo dicho por Sartre $(1952,51)$ : de qué modo se hace frente a la adversidad que el diseño urbanístico impone a la vida cotidiana. La Vaina es, así, un espacio público menor, no reconocido como tal, que contrarresta aquellos espacios públicos institucionales aportando el suyo propio. En los CSOs, y en La Vaina en concreto, lidian con el espacio realmente existente (así como con la hegemonía -el hombre capitalistarealmente existente, pues la lucha feminista es una de los pilares del espacio).

La Vaina se enmarca en esta novedosa manera de asumir el litigio político con los poderes establecidos. Estas espacialidades realizan, entonces, la tarea simbólica y material de producir lo público, de ampliar los límites de lo público institucional, que no contempla estas expresiones heterónomas. Estas maneras de comprender y emprender lo político posibilitan combatir el precepto de que lo social sólo se puede expresar en lo público (abriendo el horizonte a otros marcos relacionales e interpretativos como los comunes, por ejemplo). Además, permiten una nueva estética (no sólo en cuanto apariencia, sino también en lo que se refiere a la visibilidad, a que más gente se sienta interpelada por el espacio ocupado y sus actividades) y una accesibilidad más atractiva, superando la histórica marginación del movimiento okupa. Ese llamado a reunirse y politizarse se conecta directamente con el derecho a la ciudad.

Los integrantes conciben el centro como un experimento transversal que se funda en tres ejes: el antifascismo, el anticapitalismo y el feminismo (la imagen del CSO es una vaina en la que cada elemento representa una lucha). 
Estos ejes comprenden el espíritu del Centro, que lejos de ser una transversalidad acrítica, impone unas "líneas rojas" a, por ejemplo, partidos reformistas o de ideologías que no respetan los colectivos minorizados. Según una de las iniciadoras del proyecto autogestionado, es un espacio que contiene unas ciertas actitudes y tendencias:

La gente que compone La Vaina, la asamblea gestora ${ }^{10}$, somos gente que estamos politizadas pero cada uno tiene su ideología y no somos de una ideología, una línea concreta (...) cada uno tiene su ideología y no somos una ideología, una línea concreta. Hay tanto comunistas ${ }^{11}$ como anarquistas

No hay una causa que patrimonialice La Vaina, pero tampoco es una nave a la deriva. Para eso decidieron eliminar los símbolos políticos de la fachada, para transmitir que es un espacio normal, accesible. Algunos lo han definido -se han definido- como un lugar a medio camino entre un CSO y un Casal Popular, un espacio donde no hay reuniones clandestinas, más cercano a un Casal de barrio (no tan ideológico, enfocado al barrio), pero con un funcionamiento autogestionado y asambleario más propio de los Centros Sociales Okupados. En palabras de HJHLv2, "si okupem, no només estem farts perquè com joves no es deixen desenvolupar-nos, sinó que també no volem fer un casal de joves sinó un casal pel barri".

El Centro es igualmente un artefacto ofensivo que prepara charlas y proyecciones de películas sobre diversos temas. Durante un tiempo fue la sede del Espai Autogestionat d'Autoaprenentatge (EAdA), en el que colaboraban entidades externas (la Universidad Indignada (UI15M)) y ofrecían ciclos de formación sobre cuestiones sociopolíticas de actualidad.

El CSO La Vaina es un buen ejemplo de un Centro Social de segunda generación (Carmona, Herreros, Sánchez, Cedillo y Sguiglia 2008) que prefiere la forma-red que un autoencerramiento territorial. En ese sentido, el espacio se ha involucrado en diferentes campañas y luchas que se han llevado en el barrio y zonas aledañas, como Stop Pujades -por la rebaja del precio del transporte público-, No és pobresa, és injustícia -para visibilizar la lucha del distrito más empobrecido de Barcelona-, la Crida LGTBI (cuya presentación fue en La Vaina) o algunas luchas de ámbito estatal como la campaña contra la Ley Mordaza. Por lo tanto, La Vaina es un artefacto híbrido o en el que cooperan 'nuevas' y 'viejas' formas de hacer. Las kafetas antirrepresivas se combinan con conciertos de luces tenues y música suave.

10 A diferencia de Can Masdeu (que además de la asamblea, tiene comisiones y toda una serie de ritos para mejorar la convivencia), La Vaina carece de las complejidades organizativas (por tamaño, porque no es vivienda estable, por recorrido y experiencia), de modo que la estructura prácticamente se reduce a la asamblea gestora y otra asamblea de los colectivos que utilizan el espacio para hablar de usos, limpieza y otras cuestiones logísticas y de convivencia. Este 'organigrama' da pie a menos conflictos.

11 El entrevistado HJHLv2, por ejemplo, dejaba filtrar su filiación comunista en el uso del lenguaje, con fórmulas como "elevar la conciencia", "movimientos reformistas", "la forma más científica" o "trabajadores alienados versus vanguardia revolucionaria". 
Una vez okupado el espacio, hubo que acondicionarlo. Al haber estado abandonado se encontraba en un estado deplorable, con humedades, polvo, ratas y un desorden, incluso arquitectónico, que los iniciadores del proyecto tuvieron que solventar con mucho trabajo. Esta fue una de las primeras lecciones de lo que conllevaba tomar un espacio y hacerlo público, que okupar no es lo más difícil, lo difícil es la constancia, la permanencia del proyecto. Hay un enemigo más fuerte que la policía, y es un enemigo interno: la pereza o la apatía. Un mal uso del CSO puede llevar a que se convierta en un espacio privado, en cuanto el colectivo no se esfuerza en abrirse, en que el espacio y sus actividades sean accesibles.

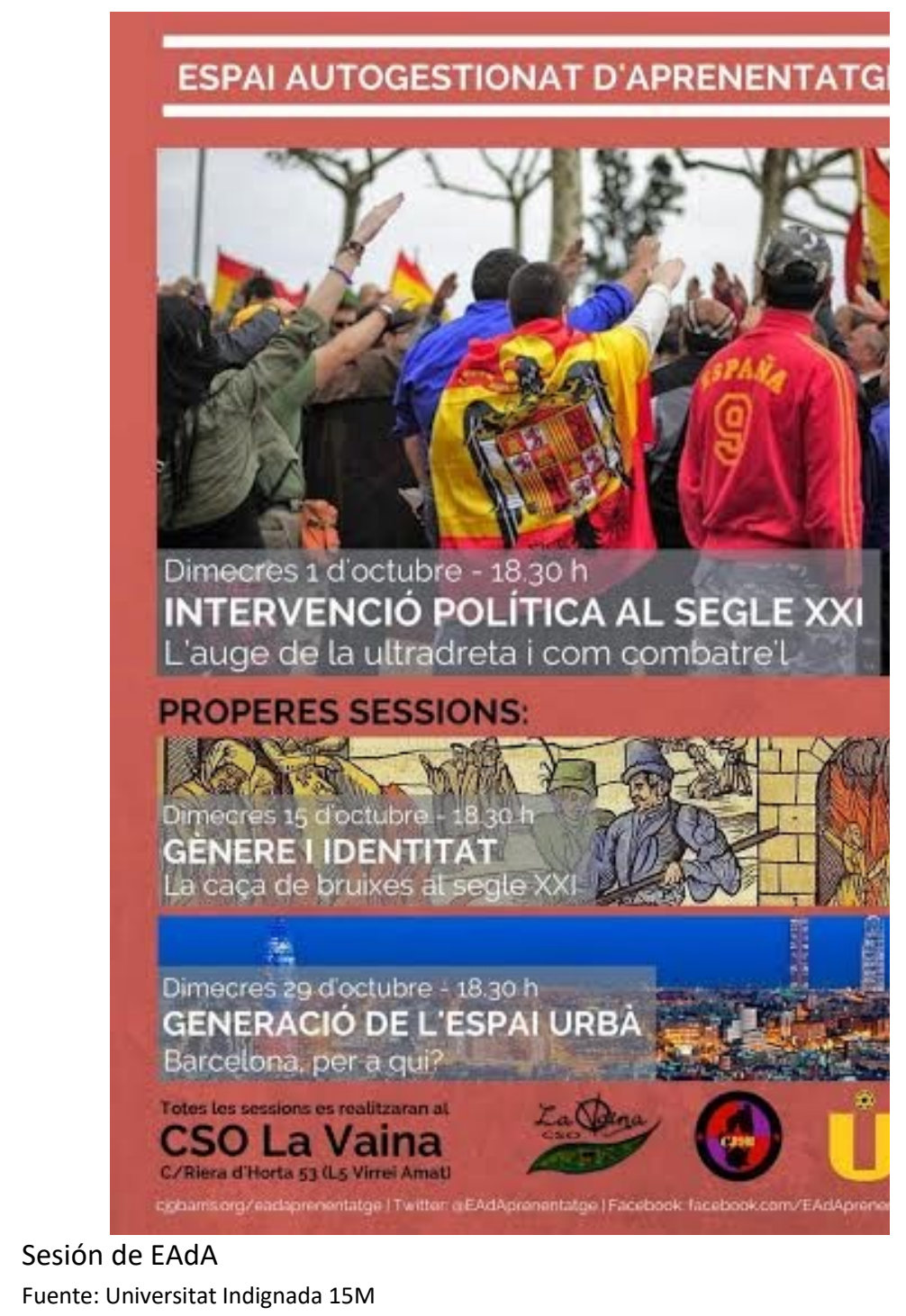

Mantener la función social (en este caso un claro servicio al barrio) del Centro exige un esfuerzo y una crítica constantes.

En la labor de repensarse y de fomentar una inclusión mayor, los habitantes que impulsaban y sostenían el proyecto optaron por abrirse, tanto en lo referente a la composición interna como a las actividades que se organizaban. Por eso, generaron debate sobre el uso del espacio, sobre qué uso darle y qué uso es el más cercano a un uso público, 
atractivo. Así, más allá de que una kafeta antirrepresiva a priori no le resulte atractiva a un octogenario, lo que se esforzaron en definir fue qué se consideraba un uso no-público. ¿Puesto que no hay espacios para divertirse, se podía venir un grupo de amigos a hacer fiesta al Centro? ¿La cena de un colectivo tiene prioridad sobre una kafeta? Tras debatir y deliberar consensuaron unos mínimos, igual que ocurre en otros espacios similares, en los que definieron las prioridades del espacio (por ejemplo, una kafeta, que se considera de uso público, tiene preferencia sobre la cena de un colectivo). Tal como explica MJHLv1

\begin{abstract}
En La Vaina no hay nadie que hable por encima de... o que haya... Así como esto yo lo he vivido en la asamblea de Joves, en La Vaina somos gente que estamos bastante empoderadas y si entra gente de fuera se le da voz, se le dice y tú qué opinas, hacemos rueda... No hablan los mismos (...) En noviembre u Octubre, por ahí le dije a una chica de la asamblea de La Sagrera que se metiera. ¿Qué pasa? Que la primera asamblea pues la chica estaba cohibida pero ahora no tiene nada que ver. ¿Por qué? Pues porque nos enfocamos a ello. Yo le decía: Tú, tú venga ¿qué opinas, qué tal? Entonces ella va cogiendo... Al principio era... No se lo sentía como suyo, ella me lo decía y ahora es como ¡ostia! Formo parte de algo
\end{abstract}

Todas estas normas se han ido acordando con el tiempo, a través del debate, y puesto que es un espacio reciente han incluido una diversidad de temas, desde si se puede beber fuera o hasta qué hora se puede, hasta el tema de la sexualidad. El derecho a la ciudad también se conquista mediante el debate y la toma de conciencia.

Asimismo, y huyendo de un eventual uso inadecuado del Centro que lo pervirtiera en un espacio exclusivo y privado, los miembros trataron de conectar con el barrio y con el vecindario. Hicieron asambleas abiertas para que la gente les conociera. Jugaban la baza de ser gente del barrio, de demostrar que han abierto un espacio de encuentro en el barrio sin esperar a las instituciones, tratando de normalizar su situación (que de por sí es anómala, al estar okupado). Trabajaron las relaciones con los vecinos, los convocaron y se acercaron a ellos. Para la habitante MJHLv1 
nosotros lo que intentamos hacer es un poco inserción que cuesta, cuesta mucho porque... Yo me acuerdo cuando era más joven que entraba por un CSO, cuando tenía 18 años y ni me fijaba, ni me acercaba, ni se me ocurría acercarme. Claro yo me pongo en la piel de esas personas y... Pero luego por ejemplo otros casos de amigos nuestros que han crecido con nosotras de traerlos a La Vaina porque había una Kafeta o porque había algo y al principio reticentes; no, no yo ahí no voy porque es un centro social okupado, yo de okupas no quiero saber nada ¿porqué? Porque hay un estereotipo de okupas punki y guarro y ¿qué pasa? Que esta gente ha entrado y ya no piensa lo mismo, gente de familia de derechas ha entrado ahí, gente de familia tal... y poco a poco eso es lo bueno que tiene

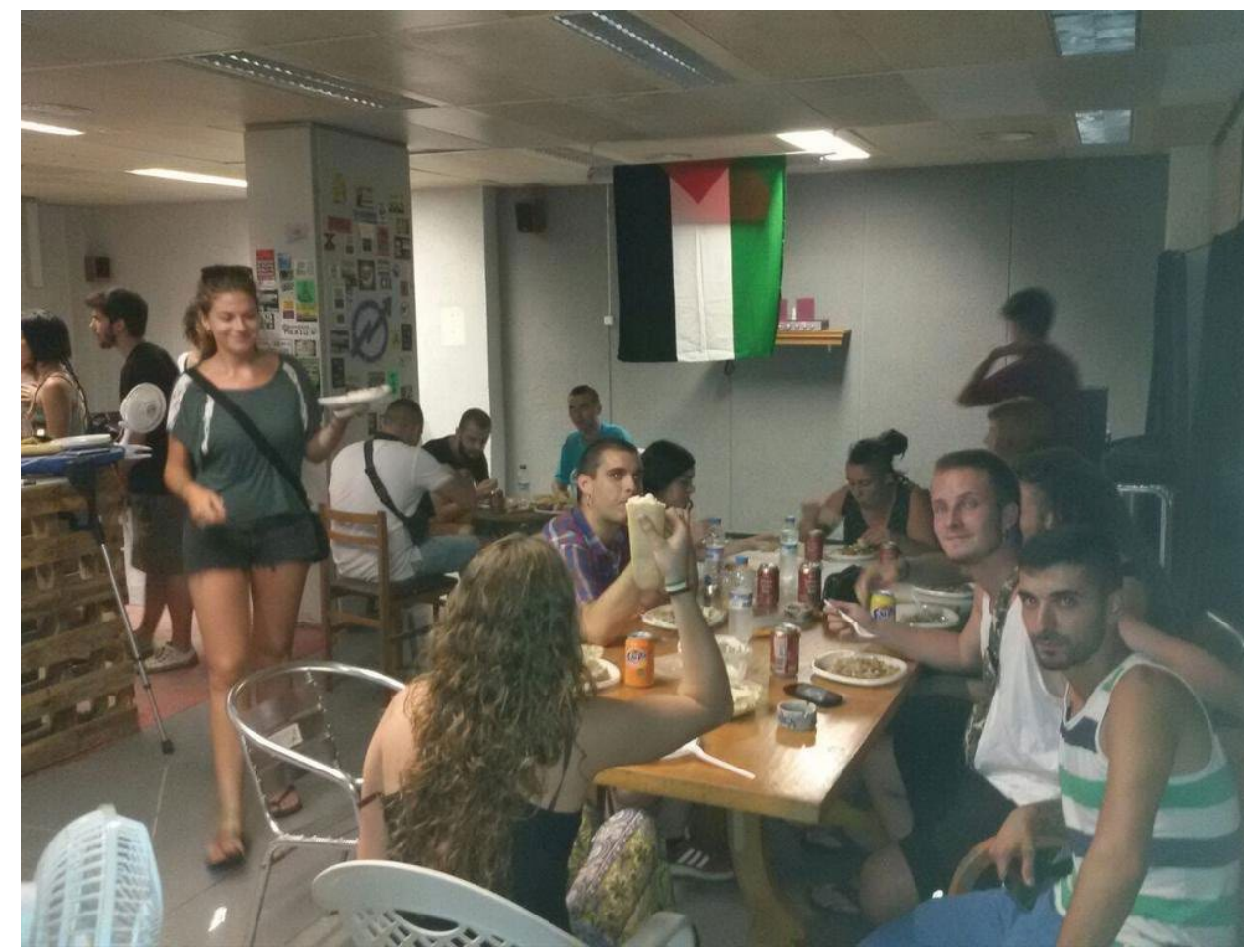

Cena sobre Palestina

23 de julio de 2015

En todo momento mostraron ser parte de la comunidad de vecinos y expresaron por activa y por pasiva que cada vez que lo necesitaran iban a tener La Vaina abierta, porque consideran que el espacio no es patrimonio del barrio, sino que es del barrio.

tenemos una buena relación con el vecino que toca a la habitación con La Vaina, que tenemos una habitación al lado de la sala de fiestas de La Vaina (...) tenía miedo de venir, un día vino el presidente de la comunidad de vecinos de al lado, nos lo comentó, picamos a su puerta, fuimos a hablar con él nosotros (HJHLv1)

De todas maneras, y al igual que ocurre en Can Masdeu, en el barrio también hay quién discrepa del proyecto. Para los encuestados, HAVLv12 o HAVLv8, los okupas "son personas que podrían trabajar y viven del cuento y a costa de los demás" y no deberían "okupar lo que a uno le dé la gana. Hay que tener respeto" ${ }^{12}$. En contraste, para MAMVLv4, con el CSO "el barrio gana vida".

12 Las citas del cuestionario son respuestas literales que el investigador anotó en el momento por su relevancia. 
Por todo ello, se puede considerar que este espacio, al igual que los demás CSOs, presta un espacio de reunión y de socialización para localizar y dar forma a estas alternativas territorializadas, que interrogan a lo existente y enuncian lo posible.

\section{Límites y limitaciones}

Esta investigación tiene como objeto preguntarse sobre las posibles características de los CSOs como lanzas para disputar y repensar el derecho a la ciudad. En este sentido, la reflexión se desplaza hacia la importancia de la espacialización y el encuentro como ingredientes fundamentales de esta relectura del concepto de Henri Lefebvre. En la medida en que la investigación indaga sobre las potencialidades de estos espacios, recorre (y recurre a) la descripción de sus aspectos más positivos en referencia a relaciones sociales y visiones del mundo que ayuden a la emancipación individual y colectiva y a la apropiación de la ciudad.

Pero la investigación no es ajena a que los CSOs no son espacios 'desconflictivizados', y que como cualquier otro espacio de encuentro (un espacio abierto, en cierta manera público, sujeto a las contingencias y a las imprevisibilidades del contexto urbano), también lo son de encontronazos. En cuanto escenarios para la interacción humana, entendida como la articulación de subjetividades con agendas propias y por tanto potencialmente enfrentadas, no escapan a la naturaleza conflictual de las relaciones sociales. Aunque en estos espacios, a diferencia de los espacios públicos tradicionales, la anonimidad como refugio para la ocultación y la reserva, y como antesala para el extrañamiento mutuo necesario para la consecución de lo urbano (Delgado 2011), no es tan marcada por tratarse de lugares en los que se da una frecuentación, una habituación y un interés mutuo que atrae a personas y colectivos afines, no están exentas del consustancial conflicto a cualquier comunidad humana. De hecho, esta intimidad de las relaciones es proclive al roce y a las desavenencias a lo largo del tiempo. Las asambleas, que pueden llegar a acoger la tiranía de la no estructura, son fuentes recurrentes de conflictos.

En los casos de estudio aquí presentados ocurren hechos similares. En Can Masdeu, que ya se ha comentado que tiene una estructura organizativa más compleja que La Vaina, estos choques se producen usualmente. Para HAHCmd2, "estamos super dogmatizados (...) para mí hay dos realidades: una es la realidad cotidiana, el cotidiano. Y otra es la realidad de la iglesia, cuando todas vamos a la iglesia". Tanto es así, que en la asamblea habría cosas que no se pueden tocar, sí hablar, porque representan el corpus simbólico de La Comunidad. Ello muestra que con tal de evitar el conflicto o de establecer cauces para resolverlo se "legisla", en palabras de uno de los habitantes. Todo está protocolarizado y solo una ficción ritual puede hacer soportable una convivencia comunitaria. Obviamente, eso no significa que los conflictos y los malentendidos se enquisten sin que la comunidad maniobre para tratar de suavizarlos. Según expone MAHCmd1,

Por ejemplo, tenemos este, una L con los dedos que significa 'language', es decir: no entiendo (...) esto por ejemplo significa me estoy confundiendo, tenemos muchos signos para facilitar eso. También tenemos como pasó ayer justo en la asamblea. Había un par de personas hablando mucho, entonces el 
facilitador tiene trabajo de 'a ver, vosotros habéis hablado mucho, hay otras personas que no han abierto la boca todavía. Queréis una oportunidad para decir algo, ¿tenéis dudas?'

Las discordancias, aunque no insalvables, se repiten: la instalación de una nueva nevera, la construcción de una rampa, la distribución del agua, la utilidad y razón de ser de las letrinas, el uso y el origen de la energía, etc. (Ortiz 2020). Estos puntos de vista encontrados pueden encerrar contradicciones del proyecto mismo (Cattaneo y Gavaldà 2010); una incoherencia entre la imagen que se proyecta al exterior y la situación real. Para HAHCmd2, "si Can Masdeu tuviera una línea dogmática, sería la ecología o de la agroecología, pero caemos en contradicciones". Por ejemplo, según explica, a un nivel discursivo afirman que no puede haber coches (sí motos) delante de la casa porque puede dar una imagen equivocada de su ideal autoconstruido. En cambio, gastan mucho en viajes (aviones, coches, medios de transporte muy contaminantes), por lo que a la postre resultan más ecológicos los del barrio, porque como tienen que pagar alquiler y no tienen suficientes recursos, no pueden viajar tanto.

Por su parte, en La Vaina también se generan situaciones de malestar, en este caso por falta de organización. Algunos participantes en las actividades del Centro percibieron que, a veces, resultaba complicado acudir a las citas y compromisos ya adoptados, de modo que la seriedad o la permanencia de iniciativas como la EAdA se tambaleaban. Ello se puede achacar a su corta trayectoria, a la heterogeneidad de sus habitantes y militancias (los integrantes militan en otros lugares y tienen su tiempo y atención divididos) y a la falta de una coordinación. En una ocasión en que La Vaina se encontraba cerrada para acoger una charla ya programada, la sesión tuvo que realizarse en un bar cercano.

Estas brechas dejan a la vista las contradicciones naturales a cualquier comunidad humana y su carácter perfectible. Además, no cabe duda de la esencia no monolítica y de la gran diversidad y variabilidad de estas experiencias (y de las personas que los componen), de modo que la pretensión de esta investigación no es la totalización o generalización de estas espacialidades. Sin embargo, esto no debe ser impedimento para fijarse en las potencialidades de estos lugares y para constatar que son espacios realmente existentes para pensar y dar forma a maneras alternativas de vivir. En plena pandemia, por caso, Can Masdeu reaccionó de forma muy favorable:

A pesar de las contraindicaciones que conlleva, la intensidad emocional que supone para sus habitantes, las servidumbres de la militancia o las luchas intestinas por el control, la Comunidad cumple con las expectativas de salvaguarda ante la inseguridad sanitaria y alimentaria, de la economía neoliberal, de la anomia, de la soledad, de la deriva personal (Ortiz 2020)

\section{Los CSOs como actores para luchar el derecho a la ciudad}

El derecho a la ciudad se puede enriquecer combinándolo con apelaciones a otros conceptos con potencial transformador, como la justicia espacial o los comunes urbanos (Venturini, Değirmenci y Morales 2019). En este artículo nos fijamos en las políticas del encuentro por su potencia creativa y por cómo se engarzan con las dinámicas de los CSOs. 
Para Merrifield, el derecho a la ciudad actualizado y radicalizado sería la política del encuentro, es decir, propiciar prácticas y espacios que faciliten el encuentro. Si entendemos el encuentro en su concepción más abarcadora, como condición para la interacción, la participación y, en consecuencia, la socialización: ¿qué es el derecho a la ciudad más que el derecho de encontrarnos con el otro? La interacción es lo que pone en relación a los diferentes grupos que habitan la ciudad (Young 1990), lo que permite conocer al diferente y ampliar la visión propia de la ciudad y del mundo. El derecho a la diferencia es, así, otra cara del derecho a la ciudad (Kipfer 2008).

La necesidad de socialización es universal y pese a la diferente experiencia de lo urbano, el encontrarse construye un sustrato compartido que permite articular visiones y luchas conjuntas. Afrontar y gestionar las diferencias de manera conjunta ayuda a que se adquieran compromisos desde un sentido solidario (Purcell 2013). Justamente, para Lefebvre, la cuestión de la capacidad de la ciudad para la integración y participación es vital (Purcell 2014), ya que crear urbanismo debería ser que la ciudad se convirtiera en una tarea colectiva (Costes 2011; Molano Camargo 2016).

En este marco, los Centros Sociales Okupados abren espacios de encuentro en clave política y sin mediación institucional, donde gestionar el encuentro de otra manera. Los CSOs proveen espacios en los cuales activistas pertenecientes a diferentes movimientos sociales puedan conocerse, del mismo modo que permiten expandir la conciencia de sus participantes hacia el campo de la disidencia y la resistencia (Martínez 2011). De alguna manera, estas espacialidades son mecanismos innovadores para construir otro tipo de ciudadanía (Membretti 2007) con una base política radical e insurgente (Dikeç y Swyngedouw 2017), a la vez que productores y usuarios de redes capilares (Lorenzi Fernández 2010). En otras palabras, los Centros Sociales Okupados permiten a las personas tener una experiencia real fuera del sistema y gobernanza capitalista y les permite transformar su propio espacio circundante. Estos espacios alternativos causan una ruptura en la narrativa hegemónica de lo que es la ciudad, por lo que configuran una arena autónoma en la política urbana (Martínez 2011).

El ciclo de luchas de 2010-2011 (Tahir, Syntagma, Gezi, Sol, Zuccotti, etc.) ha demostrado la importancia de la dimensión urbana (Harvey 2013) y ha corroborado una constante histórica: que las ciudades se han acabado por convertir en catalizadoras de luchas por mantener, renovar y establecer proyectos democráticos más radicales, ya que a esta escala los impactos materiales de las políticas abstractas se vuelven patentes (Hou y Knierbein 2017).

Estas reivindicaciones y luchas se articulan mayormente en torno al destino colectivo de la ciudad, lo que nos remite una vez más a la concepción lefebvriana de derecho a la ciudad, en la cual la ciudad se entiende en cuanto la apropiación y transformación de bienes de carácter colectivo (Mansilla 2019). De hecho, la desactivación del concepto de derecho a la ciudad viene precisamente por haberlo vaciado de su componente colectivo y concreto. En su acepción original se refiere a la reestructuración radical de las relaciones sociales, políticas y económicas a partir de replantear el ámbito de la toma de decisiones en las 
ciudades, reorientando la toma de decisiones lejos del Estado y hacia la producción de espacio urbano (Purcell 2002).

Los CSOs son productores de espacio urbano porque estabilizan marcos de significado (imaginarios) y de accionar político. Son contrainstituciones que se apoyan en una espacialidad que permite la participación, la socialización, la proactividad y el epítome de todo ello, la politización y la apropiación de lo urbano. El derecho a producir lo urbano de múltiples maneras liga definitivamente la labor y espíritu de los Centros Sociales Okupados con el derecho a la ciudad, tal como se ha visto en los casos de La Vaina y de Can Masdeu. Así, se convierten en actores válidos ${ }^{13}$ para la articulación espacial del disenso y otro tipo de contrato espacial (Vradis 2020), junto con la apertura de alternativas (de la posibilidad de pensar alternativas) y del derecho a forjar otros espacios y arquitecturas de la protesta (Vasudevan 2015).

Los Centros Sociales Okupados pueden ser interpretados como amalgama de diversas prácticas sociales de apropiación espacial que, al mismo tiempo y debido a su radicalidad socializadora y su pensamiento colectivo, denuncian las alternativas disponibles de acceso a bienes urbanos básicos, de comunicación social y de intervención política local (Martínez 2003). En este sentido, el Centro Social Okupado actúa como espacialidad emancipadora urbana, ya que desde el punto de vista relacional supone una manera de distribuir el poder que en vez de crear jerarquías delegativas y de dominación, aspira a crear individuos autodeterminados dentro de colectividades solidarias. Esta atmósfera también es propicia para adentrarse en la práctica del poder, de la soberanía, cuyo ejercicio solo puede ser colectivo, ligado al otro, en condiciones de respeto, reciprocidad y ayuda mutua.

La construcción, organización y mantenimiento de estas espacialidades va inextricablemente unida a la conformación de un grupo de afinidad y al desarrollo de lazos solidarios (Kapsali 2020). A través del encuentro con otros se constituye activamente la subjetivación política y unas nociones comunes que unen a personas heterogéneas, unen sus cuerpos y sus mentes, y universalizan sus demandas (Purcell 2013; Dikeç y Swyngedouw 2017). La idea de encuentro proclama elementos que tienen afinidad y complementariedad, elementos dispuestos a colisionar, enclavarse, agarrarse entre sí (Merrifield 2012). Pero, ¿cómo sostener en el tiempo las enormes energías que se movilizan?

un momento conduce a otro momento y una política del encuentro explota cuando los momentos colisionan, colisionan en la calle. Entonces ¿cómo se puede mantener la intensidad del momento, cómo armonizarlo con una evolución política continua, con una auténtica política de transformación? (Merrifield 2011, 9)

El mismo autor se responde: la política del encuentro siempre se configura como un encuentro en alguna parte, un lugar de encuentro espacial. Estas espacialidades permiten la toma de decisiones colectiva en la definición social y física del espacio (Stavrides 2016, 215).

13 Lefebvre ya asumió que había que reconocer a otros sujetos y otros actores que trabajaran por la posesión y gestión colectivas del espacio urbano (Molano Camargo 2016). 
Por eso, la espacialidad emancipadora urbana practicada por los Centros Sociales Okupados permite disputar lo urbano, presentar batalla en la ciudad, no únicamente como escenario de la lucha, sino como campo a definir.

Así, la acción de los CSOs ha inscrito nuevos lugares en la ciudad. Gracias a ellos, pueden transferir poder y control sobre el espacio urbano y la posibilidad de incidir directamente en el andamiaje institucional y político ${ }^{14}$. Para Martínez (2020), el derecho a la ciudad se practica en esta pugna contra la exclusión de muchos grupos sociales del corazón de lo urbano y la construcción de alternativas autogestionadas en las que facilitar encuentros sociales y oportunidades de movilización política. De este modo, los Centros Sociales Okupados pueden abrir el acceso y la producción de lo urbano.

Para Lefebvre avanzamos hacia una sociedad urbana, hacia un momento en que la urbanización desterrará definitivamente a la industrialización como fuerza motriz de la historia. Pero este salto debe ser cualitativo y debe involucrar la radical transformación de la estructura social y del habitar. Él creía que era más fácil construir una ciudad que vida urbana, pero el desarrollo de la sociedad sólo la concebía en la vida urbana y con el fin de realizar de la sociedad urbana (Lefebvre 2017). La consecución de lo urbano, el elemento básico de la ciudad, es la esencia que puede posibilitar la superación de la ciudad-producto, de la sociedad burocrática de consumo dirigido, en la búsqueda (la práctica y la lucha constantes) del valor de uso. Si cada sociedad produce su espacio y en el espacio de un orden se oculta un cierto orden del espacio (Lefebvre 2013), lo urbano es la condición de posibilidad para imaginar y producir otros espacios urbanos. Lo urbano es un espacio vital que desempeña como terreno tanto para la organización de la sociedad capitalista, como para las luchas transformadoras. Para Merrifield (2013) lo urbano se convierte tanto en el lugar como en la némesis del encuentro. Él también parte de la premisa de una urbanización planetaria, y de la oportunidad que ofrece para hacer saltar las costuras capitalistas. En la perspectiva de luchar contra la alienación de la vida urbana, Merrifield hila más allá del concepto de vida cotidiana de Lefebvre y se focaliza en los espacios que permiten volver concreto lo abstracto, que imbriquen los mundos físicos y virtuales (le da mucha importancia a la esfera digital, como mediador y facilitador imprescindible para la perspectiva revolucionaria que luego aterriza en la inmanencia urbana). Estos espacios para el encuentro, son hechos públicos por las personas a fuerza de encontrarse en y entre ellos.

Los CSOs, con su defensa del valor de uso, desafían la propiedad privada de la tierra urbana que perpetúa el acto de separación entre la obra (el espacio) y el productor (la sociedad) que aliena a la mayoría de habitantes (Carlos, Faleiros de Padua y Alves 2017). De esta manera, empujan hacia la apropiación efectiva de lo urbano, ofreciendo un espacio de autonomía y de potencias individuales y colectivas, y propiciando la posibilidad del encuentro y la diferencia, y por ende, el derecho a la ciudad.

14 Superado un inicial vanguardismo y desconexión con el territorio, el movimiento de okupación incluyó nuevos repertorios de acción que influyeron en las políticas públicas (González, Cortina-Oriol y Aguilera 2019) y apuntaron a metas de 'aquí y ahora' como la defensa de la bicicleta (Lorenzi Fernández 2010) o formas de urbanismo de abajo hacia arriba, el llamado bottom-up urbanism (Serraos y Asprogerakas 2019). 


\section{Bibliografía}

Amin, Ash. 2014. "Lively Infrastructure". Theory, Culture \& Society 31 (7-8): 137-61. https://doi.org/10.1177/0263276414548490

Astudillo Salazar, Ana Elisa. 2019. "Organización vecinal desde la memoria colectiva y la liberació del espacio. Etnografía del Ágora Juan Andrés Benítez en El Raval", Papeles de relaciones ecosociales y cambio global, 146: 119-36.

Attoh, Kafui A. 2011. "What kind of right is the 'right to the city'?". Progress in Human Geography 35: 669-85.

Bekridaki, Georgia, y Antonios Broumas. 2017. "Greek society in crisis and in motion: building the material bases for an alternative society from the bottom up". Interface: a journal for and about social movements 9 (1): 230-55.

Benach, Núria. 2017. "Da desigualdade social à justiça espacial". En Justiça Espacial e o Direito à Cidade, organizado por Ana Fani Alessandri Carlos, Rafael Faleiros de Padua y Glória Alves, 15-33. São Paulo: Editora Contexto.

Bey, Hakim. 2014. TAZ. Zona Temporalmente Autónoma. Madrid: Enclave de libros.

Carabancheleando. 2017. Diccionario de las periferias. Métodos y saberes autónomos desde los barrios. Madrid: Traficantes de Sueños.

Carlos, Ana F. A., Rafael Faleiros de Padua, y Glória Alves. 2017. Justiça Espacial e o Direito à Cidade. São Paulo: Editora Contexto.

Carmona, Pablo, Tomás Herreros, Raúl Sánchez Cedillo, y Nicolás Sguiglia. 2008. "Centros Sociales: Monstruos y máquinas políticas para una nueva generación de instituciones de movimiento". En Autonomía y Metrópolis. Del movimiento okupa a los Centros Sociales de segunda generación, editado por VV.AA, 117-29. Málaga: CuadernoHerramienta.

Cattaneo, Claudio. 2014. "Quantitative historical analysis of squatted social centres in the Barcelona Metropolitan Area". Encuentro del colectivo SqEK en Roma.

Cattaneo, Claudio y Enrique Tudela. 2014. "¡El carrer és nostre! El movimiento autónomo en Barcelona, 1980-2012". En The city is ours: Squatting and Autonomous Movements in Europe from the 1970s to the Present, editado por Bart Steen, Ask Katzeff y Leendert Hoogenhuijze, 95-130. Oakland: PM Press.

Cattaneo, Claudio y Marc Gavaldà. 2010. "The experience of rurban squats in Collserola, Barcelona: what kind of degrowth?". Journal of Cleaner Production, 18 (6): 581-89.

Chatterton, Paul. 2010. "The urban impossible: A eulogy for the unfinished city". City 14 (3): 234-44.

Coppola, Alessandro y Alberto Vanolo. 2015. "Normalising autonomous spaces: Ongoing transformations in Christiania, Copenhagen". Urban Studies 52 (6): 1152-168.

Corsín, Alberto. 2014. "The Right to Infrastructure: A Prototype for Open Source Urbanism". Environment and Planning D: Society and Space 32 (3): 342-62. https://doi.org/10.1068/d13077p

Costes, Laurence. 2011. "Del 'derecho a la ciudad' de Henri Lefebvre a la universalidad de la urbanización moderna". Urban 02: 89-100. 
de Souza, Marcelo Lopes. 2010. "Which right to which city? In defence of political-strategic clarity". Interface: a journal for and about social movements 2 (1): 315-33.

Dee, E.T.C. y Galvão Delle Rodrigues. 2014. "El Banc: Squatting as Urban Struggle in Barcelona". opendemocracy.net.

del Viso, Nuria, José Luis Fernández Casadevante, y Morán, Nerea. 2017. "Cultivando relaciones sociales. Lo común y lo "comunitario" a través de la experiencia de dos huertos urbanos de Madrid". Revista de Antropología Social, 26 (2): 449-72.

Delgado, Manuel. 1999. El animal público. Hacia una antropología de los espacios públicos. Barcelona: Anagrama.

Delgado, Manuel. 2011. El espacio público como ideología. Madrid: Los libros de la Catarata.

Diaz-Parra Iban, y Jaime Jover. 2021. "Overtourism, place alienation and the right to the city: insights from the historic centre of Seville, Spain". Journal of Sustainable Tourism 29 (2-3): 158-75. https://doi.org/10.1080/09669582.2020.1717504

Dikeç, Mustafa, y Erik Swyngedouw. 2017. "Theorizing the Politicizing City". International Journal of Urban and Regional Research 41 (1): 1-18. https://doi.org/10.1111/14682427.12388

Diz, Carlos. 2017. "Los otros lugares de la política. Activismo, centros sociales y democracia". En Hacia una (re)conceptualización de la democracia contemporánea, editado por Roberto C. Cuenca Jiménez, Walter Federico Gadea y Diego Allen-Perkins, 143-61. Sevilla: Fénix Editora.

Fernández Gómez, Francisco de Paula. 2010. Okupació a Catalunya (1984-2009). Barcelona: Edicions Anomia.

Garcés, Marina. 2006. "Encarnar la crítica. Algunas tesis. Algunos ejemplos". Kritik 06

García Puchades, Wenceslao, y Mijo Miquel. 2016. La cultura de lo común: prácticas colectivas del siglo XXI. Valencia: Universitat Politècnica de València.

Garnier, Jean-Pierre. 2006. Contra los territorios del poder. Barcelona: Virus.

Garnier, Jean-Pierre. 2012. "El derecho a la ciudad desde Henri Lefebvre hasta David Harvey. Entre teorizaciones y realización", Ciudades, 15 (1): 217-25.

Gerlofs, Ben. 2020. "Dreaming dialectically: The death and life of the Mexico City charter for the right to the city". Urban Studies 57 (10): 2064-079. https://doi.org/10.1177/0042098019868102

Gil Álvarez, Esther. 2017. "La economía del compartir: nuevas prácticas y sus implicaciones en el entorno urbano". Lurralde. Investigación y Espacio 40: 15-42.

González, Robert. 2004. "La okupación y las políticas públicas: negociación, legalización y gestión local del conflicto urbano". En ¿Dónde están las llaves? El movimiento okupa: prácticas y contextos sociales, coordinado por Ramón Adell y Miguel Ángel Martínez, 151-78). Madrid: La Catarata.

González, Robert y Alejandra Araiza. 2016. "Feminismo y okupación en España: El caso de la Eskalera Karakola". Sociológica (México) 31 (87): 207-236. 
González, Robert, Mercè Cortina-Oriol, y Thomas Aguilera. 2019. "Movimientos de okupación y políticas públicas urbanas: los casos de Madrid, Barcelona y Bilbao". Revista especializada en investigación jurídica 3 (5): 8-38.

González, Robert, Miguel Á. Martínez, y Oriol Barranco. 2018. "Autogestión de equipamientos $\mathrm{y}$ espacios urbanos: los centros sociales okupados $\mathrm{y}$ autogestionados". En Movimientos sociales y derecho a la ciudad. Creadores de democracia radical, editado por Pedro Ibarra, Ricard Gomà, Salvador Martí y Robert González, 88-103. Barcelona: Icaria.

Goonewardena, Kanishka. 2011. "Henri Lefebvre y la revolución de la vida cotidiana, la ciudad y el Estado". Urban 02: 25-39.

Gray, Neil. 2018. "Beyond the Right to the City: Territorial Autogestion and the Take over the City Movement in 1970s Italy". Antipode 50: 31939. https://doi.org/10.1111/anti.12360

Gutiérrez Barbarrusa, Virginia F. 2004. "Okupación y movimiento vecinal". En ¿Dónde están las llaves? El movimiento okupa: prácticas y contextos sociales, coordinado por Ramón Adell y Miguel Ángel Martínez, 115-28. Madrid: Catarata.

Hardt, Michael, y Antonio Negri. 2004. Multitud. Guerra y democracia en la era del Imperio. Madrid: Debate.

Harvey, David. 2008. "El derecho a la ciudad". New Left Review 53: 23-39.

Harvey, David. 2013. Ciudades rebeldes. Del derecho de la ciudad a la revolución urbana. Madrid: Akal.

HIC-AL. 2008. El Derecho a la Ciudad en el mundo. Ciudad de México: Coalición Internacional para el Hábitat.

Hou, Jeffrey, y Sabine Knierbein (eds.). 2017. City Unsilenced: Urban Resistance and Public Space in the Age of Shrinking Democracy. Londres: Routledge.

Iveson, Kurt. 2013. "Cities within the city: Do-it-yourself urbanism and the right to the city". International Journal of Urban and Regional Research 37: 941-56.

Kapsali, Matina. 2020. "Political infrastructures of care: Collective home making in refugee solidarity squats". Radical Housing Journal 2 (2): 13-34.

Kipfer, Stefan. 2008. "How Lefebvre urbanized Gramsci: hegemony, everyday life, and difference". En Space, difference, everyday life. Reading Henri Lefebvre, editado por Kanishka Goonewardena, Stefan Kipfer, Richard Milgrom y Christian Schmid, 193212. Nueva York: Routledge.

Koster, Martijn, y Monique Nuijten. 2016. "Coproducing urban space: Rethinking theformal/informal dichotomy". Singapore Journal of Tropical Geography 37: 282-94.

Lebuhn, Henrik. 2017. "Shifting struggles over public space and public goods in Berlin. Urban activism between protest and participation". En City unsilenced. Urban resistance and public space in the age of shrinking democracy, editado por Jeffrey Hou y Sabine Knierbein. Nueva York: Routledge.

Lefebvre, Henri. 2017. El derecho a la ciudad. Madrid: Capitán Swing.

Lefebvre, Henri. 2013. La producción del espacio. Madrid: Capitán Swing. 
Lorenzi Fernández, Elísabeth. 2010. "Los talleres de auto-reparación de bicicletas en los espacios autogestionados". En Okupaciones en movimiento: derivas, estrategias y prácticas, editado por Mario D. Sánchez-Pinilla, Miguel Á. Martínez López y Elisabeth Lorenzi Fernández, 133-85. Madrid: tierradenadie ediciones.

Mahabir, Ron, Andrew Crooks, Arie Croitoru, y Peggy Agouris. 2016. "The study of slums as social and physical constructs: challenges and emerging research opportunities". Regional Studies, Regional Science 3 (1): 399-419. https://doi.org/10.1080/21681376.2016.1229130

Makrygianni, Vaso, y Charalampos Tsavdaroglou. 2015. "The right to the city' in Athens during a crisis era. Between inversion, assimilation and going beyond". En City of Crisis. The Multiple Contestation of Southern European Cities, editado por Frank Eckardt y Javier Ruiz Sánchez. Urban Studies.

Mansilla, José. 2019. "Presentació". En Del civisme al dret a la ciutat: repolitització de la vida en comú a la ciutat del segle XXI, editado por Sandra Ezquerra, Maria de Eguía y Elisa Covelo, 219-23. Barcelona: Icaria.

Marcuse, Peter. 2009. "From critical urban theory to the right to the city". City 13 (2/3): 185-97. https://doi.org/10.1080/13604810902982177

Marinas Sánchez, Marina. 2004. "Derribando los muros del género: mujer y okupación". En ¿Dónde están las llaves? El movimiento okupa: prácticas y contextos sociales, coordinado por Ramón Adell y Miguel Ángel Martínez, 205-27. Madrid: Catarata.

Martínez, Miguel Á. 2003. "Viviendas y Centros Sociales en el movimiento de okupación: entre la autogestión doméstica y la restructuración urbana". Scripta Nova. Revista electrónica de Geografía y Ciencias Sociales 146 (109).

Martínez, Miguel Á. 2004. "Del urbanismo a la autogestión: una historia posible del movimiento de okupación en España". En ¿Dónde están las llaves? El movimiento okupa: prácticas y contextos sociales, coordinado por Ramón Adell y Miguel Ángel Martínez, 61-88. Madrid: Catarata.

Martínez, Miguel Á. 2007. "El Movimiento de Okupaciones: Contracultura Urbana y Dinámicas Alter-Globalización". Revista de estudios de juventud, 76: 225-43.

Martínez, Miguel Á. 2010a. "El movimiento de okupaciones: una larga e inquietante existencia". Viento Sur 108: 43-8.

Martínez, Miguel Á. 2010b. "Los procesos de institucionalización en el movimiento de okupaciones. Estrategias, discursos y experiencias". En Okupaciones en movimiento: derivas, estrategias y prácticas, editado por Mario D. Sánchez-Pinilla, Miguel Á. Martínez López y Elisabeth Lorenzi Fernández, 53-132. Madrid: tierradenadie Ediciones.

Martínez, Miguel Á. 2011. "The Struggle for Social Autonomy: What Have We Learnt about Urban Politics from Squatting in Europe?". En International RC21 conference "The struggle to belong. Dealing with diversity in 21st century urban settings.'. Amsterdam, 7 al 9 de julio. 
Martínez, Miguel Á. 2020. Squatters in The Capitalist City. Housing, Justice, and Urban Politics. New York and London: Routledge/Taylor \& Francis Group.

Martínez, Miguel Á. y Claudio Cattaneo. 2014. "Squatting as an Alternative to Capitalism. An introduction". En The Squatters' movement in Europe. Commons and Autonomy as Alternatives to Capitalism, editado por Squatting Europe Kollective, 1-25. Londres: Pluto Press.

Mayer, Margit. 2009. "The 'right to the city' in the context of shifting mottos of urban social movements". City 13 (2/3): 362-374. https://doi.org/10.1080/13604810902982755

McFarlane, Colin. 2008. "Urban Shadows: Materiality, the 'Southern City' and Urban Theory". Geography Compass (2) 2: 340-58.

Membretti, Andrea. 2007. "Centro Sociale Loncavallo. Building Citizenship as an innovative service". European urban and Regional Studies 14 (3): 255-66.

Méndez, Ricardo. 2015. "Redes de colaboración y economía alternativa para la resiliencia urbana: una agenda de investigación". Biblio 3W. Revista Bibliográfica de Geografía y Ciencias Sociales XX (1.139).

Merrifield, Andy. 2011. "The Right to the City and Beyond: Notes on a Lefebvrian ReConceptualization". City 14 (3-4): 473-81. https://doi.org/10.1080/13604813.2011.595116

Merrifield, Andy. 2012. "The politics of the encounter and the urbanization of the world". City 16 (3): 269-83. http://dx.doi.org/10.1080/13604813.2012.687869

Merrifield, Andy. 2013. The Politics of the Encounter: Urban Theory and Protest Under Planetary Urbanization. Athens: University of Georgia Press.

Molano Camargo, Frank. 2016. "El derecho a la ciudad: de Henri Lefebvre a los análisis sobre la ciudad capitalista contemporánea". Revista Folios 44: 3-19.

Moore, Alan y Alan Smart. 2015. Making Room: Cultural Production in Occupied Spaces. Barcelona: Making Room/Malditos Impresores.

Mudu, Pierpaolo. 2004. "Resisting and Challenging Neoliberalism: The Development of Italian Social Centers". Antipode. A Radical Journal of Geography 36 (5): 917-41.

Mundial, Foro Social. 2005. "Carta Mundial por el Derecho a la Ciudad". Cuadernos Geográficos 52: 368-80.

Musset, Alain. 2015. "De los lugares de espera a los territorios de la espera. ¿Una nueva dimensión de la geografía social?". Documents d'Anàlisi Geogràfica 61 (2): 305-24.

Navarro, Javier. 2016. Los ateneos libertarios en España (1931-1939). Madrid: La Neurosis o Las Barricadas Ed.

Navas, María Gabriela y Muna Makhlouf (coords.). 2018. Apropiaciones de la ciudad. Género y producción urbana: la reivindicación del derecho a la ciudad como práctica espacial. Barcelona: Pol·len edicions.

Ortiz, Mikel. 2020. La Comunidad. Estudio antropológico de una experiencia alternativa de vida comunitaria en la Sierra de Collserola de Barcelona: Can Masdeu. Trabajo de Fin de Máster. No publicado (inédito). Comunicación personal del autor. 
Oslender, Ulrich. 2002. "Espacio, lugar y movimientos sociales: hacia una 'espacialidad de resistencia'". Scripta Nova. Revista electrónica de geografía y ciencias sociales, 7 (115).

Paba, Giancarlo, y Camilla Perrone. 2017. "Place matters: spatial implications of postmetropolitan transition". En Post-Metropolitan Territories and Urban Space, editado por Alessandro Balducci, Valeria Fedeli y Francesco Curci, 256-66. Oxford: Routledge.

Pradilla Cobos, Emilio. 2009. "La mundialización, la globalización imperialista y las ciudades latinoamericanas". Revista Bitácora Urbano Territorial 15 (2): 13-36.

Pruijt, Hans. 2003. "Is the institutionalization of urban movements inevitable? A comparison of the opportunities for sustained squatting in New York City and Amsterdam". International Journal of Urban and Regional Research 27 (1): 133-157.

Pruijt, Hans y Conny Roggeband. 2014. "Autonomous and/or Institutionalized Social Movements? Conceptual Clarification and Illustrative Cases". International Journal of Comparative Sociology 55(2): 144-65.

Purcell, Mark. 2002. "Excavating Lefebvre: The right to the city and its urban politics of the inhabitant". GeoJournal 58:99-108. https://doi.org/10.1023/B:GEJ0.0000010829.62237.8f

Purcell, Mark. 2013. "The Right to the City: The Struggle for Democracy in the Urban Public Realm". Policy \& Politics 41 (3): 311-27.

Purcell, Mark. 2014. "Possible worlds: Henri Lefebvre and the right to the city". Journal of Urban Affairs 36: 141-54. https://doi.org/10.1111/juaf.12034

Ruggiero, Vincenzo. 2000. "New social movements and the 'centrisociali' in Milan". The Sociological Review 48 (2): 167-85.

Sargisson, Lucy. 2007. "Strange Places: Estrangement, Utopianism, and Intentional Communities". Utopian Studies 18 (3): 393-424.

Sartre, Jean-Paul. 1952. Saint Genet, comédien et martyr. Paris: Gallimard.

Schehr, Robert C. (1997). Dynamic Utopia: Establishing Intentional Communities as a New Social Movement. Westport: Bergin \& Garvey.

Serraos, Konstantinos, y Evangelos Asprogerakas. 2019. "Typologies of Bottom-Up Planning in Southern Europe: The Case of Greek Urbanism During the Economic Crisis". En The Palgrave Handbook of Bottom-Up Urbanism, editado por Mahyar Arefi y Conrad Kickert, 163-75. Cham: Palgrave Macmillan.

Simone, Abdoumaliq. 2005. "The right to the city". Interventions: International Journal of Postcolonial Studies 7 (3): 321-25.

https://doi.org/10.1080/13698010500268189

Stavrides, Stavros. 2007. "Espacialidades de emancipación y la 'ciudad de umbrales'". Bajo el volcán 7 (11): 117-24.

Stavrides, Stavros. 2014. "Emerging common spaces as a challenge to the city of crisis". City. Analysis of urban trends, culture, theory, policy, action, 18 (4-5): 546-50.

Stavrides, Stavros. 2016. Hacia la ciudad de umbrales. Madrid: Akal.

Steen, Bart, Ask Katzeff, y Leendert Hoogenhuijze (eds.). 2014. The city is ours: Squatting and Autonomous Movements in Europe from the 1970s to the Present. Oakland: PM Press. 
Tutor Anton, Aritz (2020). "Barcelona okupa! Una posible historia de la okupación en Barcelona". Inguruak, 68: 78-95.

Uitermark Justus, Walter Nicholls, y Maarten Loopmans. 2012. "Cities and Social Movements: Theorizing beyond the Right to the City". Environment and Planning A: Economy and Space 44 (11): 2546-2554. https://doi.org/10.1068/a44301

Vasudevan, Alexander. 2015. "The autonomous city: Towards a critical geography of occupation". Progress in Human Geography 39 (3): 316-37.

Vasudevan, Alexander. 2017. The Autonomous City: A History of Urban Squatting. Londres: Verso.

Venturini, Federico, Emet Değirmenci, e Inés Morales (eds.). 2019.The right to the city and social ecology: towards democratic and ecological cities. Montreal: Black Rose Books.

Vradis, Antonis. 2020. "Spatial politics and the spatial contract in Exarcheia, Athens, Greece (1974-2018)". Trans Inst Br Geogr 45 (3): 542-58. https://doi.org/10.1111/tran.12359

Wigle, Jill, y Lorena Zárate. 2010. "Mexico City creates charter for the Right to the City". Progressive Planning 184: 13-16.

Young, Iris M. 1990. Justice and the Politics of Difference. NJ: Princeton University Press.

(C) Copyright Aritz Tutor Anton, 2021

(C) Copyright: Scripta Nova, 2021. 
Ficha bibliográfica:

TUTOR ANTON, Aritz. Re(pensando) el derecho a la ciudad desde los centros sociales okupados. Scripta Nova. Revista Electrónica de Geografía y Ciencias Sociales. Barcelona: Universitat de Barcelona, vol. 25, Núm. 4(2021), p. 147-182. ISSN: 1138-9788]

DOI: $10.1344 / \operatorname{sn} 2021.25 .33604$ 